NBER WORKING PAPER SERIES

SKILL BIASED HETEROGENEOUS FIRMS, TRADE LIBERALIZATION, AND
THE SKILL PREMIUM

James Harrigan

Ariell Reshef

Working Paper 17604

http://www.nber.org/papers/w17604

\author{
NATIONAL BUREAU OF ECONOMIC RESEARCH \\ 1050 Massachusetts Avenue \\ Cambridge, MA 02138 \\ November 2011
}

We thank the Bankard Fund for Political Economy at the University of Virginia for support. We thank John McLaren, Maxim Engers, Eric Young, Latchezar Popov, Çaglar Özden, and seminar audiences in North America and Europe for helpful comments and suggestions. The views expressed herein are those of the authors and do not necessarily reflect the views of the National Bureau of Economic Research.

NBER working papers are circulated for discussion and comment purposes. They have not been peerreviewed or been subject to the review by the NBER Board of Directors that accompanies official NBER publications.

(C) 2011 by James Harrigan and Ariell Reshef. All rights reserved. Short sections of text, not to exceed two paragraphs, may be quoted without explicit permission provided that full credit, including $₫$ notice, is given to the source. 
Skill Biased Heterogeneous Firms, Trade Liberalization, and the Skill Premium

James Harrigan and Ariell Reshef

NBER Working Paper No. 17604

November 2011, Revised June 2012

JEL No. F1,F16,J3,J31

\begin{abstract}
$\underline{\text { ABSTRACT }}$
We propose a theory that rising globalization and rising wage inequality are related because trade liberalization raises the demand facing highly competitive skill-intensive firms. In our model, only the lowest-cost firms participate in the global economy exactly along the lines of Melitz (2003). In addition to differing in their productivity, firms differ in their skill intensity. We model skill-biased technology as a correlation between skill intensity and technological acumen, and we estimate this correlation to be large using firm-level data from Chile in 1995. A fall in trade costs leads to both greater trade volumes and an increase in the relative demand for skill, as the lowest-cost/most-skilled firms expand to serve the export market while less skill-intensive non-exporters retrench in the face of increased import competition. This mechanism works regardless of factor endowment differences, so we provide an explanation for why globalization and wage inequality move together in both skill-abundant and skill-scarce countries. In our model countries are net exporters of the services of their abundant factor, but there are no StolperSamuelson effects because import competition affects all domestic firms equally.
\end{abstract}

James Harrigan

Department of Economics

University of Virginia

P.O. Box 400182

Charlottesville, VA 22904-4182

and NBER

harrigan@nber.org

Ariell Reshef

University of Virginia

Department of Economics

P.O. Box 400182

Charlottesville, VA 22904-4182

ariellr@virginia.edu 


\title{
Skill biased heterogeneous firms, trade liberalization, and the skill premium
}

\author{
James Harrigan \\ University of Virginia and NBER \\ and \\ Ariell Reshef \\ University of Virginia
}

Version: May, 2012

We propose a theory that rising globalization and rising wage inequality are related because trade liberalization raises the demand facing highly competitive skill-intensive firms. In our model, only the lowest-cost firms participate in the global economy exactly along the lines of Melitz (2003). In addition to differing in their productivity, firms differ in their skill intensity. We model skill-biased technology as a correlation between skill intensity and technological acumen, and we estimate this correlation to be large using firm-level data from Chile in 1995. A fall in trade costs leads to both greater trade volumes and an increase in the relative demand for skill, as the lowest-cost/most-skilled firms expand to serve the export market while less skill-intensive non-exporters retrench in the face of increased import competition. This mechanism works regardless of factor endowment differences, so we provide an explanation for why globalization and wage inequality move together in both skill-abundant and skill-scarce countries. In our model countries are net exporters of the services of their abundant factor, but there are no Stolper-Samuelson effects because import competition affects all domestic firms equally.

Key Words: skill premium, skill bias, trade liberalization, heterogeneous firms, factor endowments, Heckscher-Ohlin, Stolper-Samuelson.

Subject Classification: F1, F16, J3, J31.

\section{INTRODUCTION}

Two of the most striking trends in the global economy since 1970 are globalization and increasing wage inequality. For example, in the United States, the premium that college graduates earn over high school graduates grew by 35 percentage points between 1971 and 2005 (Autor, Katz, and Kearney (2008)). Over the same period, the ratio of trade to GDP in the U.S. grew 15 percentage points. ${ }^{2}$ Similar trends are apparent around the world, including in many developing countries (Goldberg and Pavcnik (2007)). This raises an important but difficult question for applied economics: has increased globalization contributed to growing wage inequality? More precisely, have reductions in the costs of cross-border transactions led to both greater globalization and increased wage inequality?

There is a large, fascinating, and inconclusive literature on this question. The primary alternative hypothesis is technological: skill-biased technological change, especially when embodied in information and communications technology investment, has led to an increased relative demand for more educated workers (see, for example, Autor, Levy, and Murnane (2003)). In this view, globalization is a sideshow, having only a small effect on the skill premium, at least in the United States.

In this paper we revisit this question using a novel approach. In our model, firms are heterogeneous in their productivity, and only the lowest-cost firms participate in the global economy, exactly along the

\footnotetext{
${ }^{1}$ Department of Economics, University of Virginia, Charlottesville, VA 22904, james.harrigan@virginia.edu, ariellr@virginia.edu. We thank the Bankard Fund for Political Economy at the University of Virginia for support. We thank John McLaren, Maxim Engers, Eric Young, Latchezar Popov, Çaĝlar Őzden, and seminar audiences in North America and Europe for helpful comments and suggestions.

${ }^{2}$ Our calculations, from United States National Accounts.
} 
lines of Melitz (2003). In addition to differing in their productivity, firms in our model differ in their skill intensity. We model skill-biased technology as a correlation between skill intensity and technological acumen, a specification strongly supported by both data and theory. There is a large body of work that indicates that throughout the 20th century newer and more efficient technologies have typically demanded more skilled (or better educated) workers; see Goldin and Katz (2008) and references therein. Acemoglu (2002) provides a theoretical framework to explain this phenomenon, as well as the acceleration in the bias in favor of skilled labor post 1979 in the U.S. New technologies are embodied in new goods, and Xiang (2005) shows that new goods have higher skill intensity. Abowd, Haltiwanger, Lane, McKinney, and Sandusky (2007) find a strong positive correlation between advanced technology and skill (both measured in various ways) in a cross-sectional analysis of U.S. firms.

Skill-biased technological heterogeneity implies that, on average, the most competitive firms are also the most skill-intensive. As a consequence, a fall in trade costs leads to both greater trade volumes and an increase in the relative demand for skill, as the lowest-cost/most-skilled firms expand to serve the export market while less skill-intensive non-exporters retrench in the face of increased import competition. Thus, trade liberalization leads directly to both greater trade volumes and an increase in the demand for skill. Crucially, as long as productivity and skill intensity are positively correlated around the world, this mechanism works regardless of factor endowment differences. Thus, we provide an explanation for why globalization and wage inequality move together in both skill-abundant and skill-scarce countries.

Some other models also predict that trade liberalization may increase the skill premium globally, including Feenstra and Hanson (1985), Acemoglu (2003), Zhu and Trefler (2005), and Burstein and Vogel (2010). What is new in our model is the interaction between skill intensity, factor endowment differences, and firm heterogeneity. This means that our model is consistent with the evidence on firm-level heterogeneity and exporting (see Bernard, Jensen, Redding, and Schott (2007) for a lucid discussion of this evidence).

In our numerical analysis, we calibrate the model to firm-level data from a small open economy, Chile in 1995. Using the calibrated model, we show how multilateral trade liberalization raises average productivity and real GDP, and also increases the skill premium in both skill-abundant and skill-scarce countries.

Our paper builds on a large theoretical and empirical literature in international trade and labor economics. Two recent papers are most closely related to ours. Bernard, Redding, and Schott (2007) connect the Melitz model to the classic $2 \times 2 \times 2$ Heckscher-Ohlin-Samuelson model, and thereby integrate factor endowment differences with firm-level productivity and factor intensity differences. The model of Bernard, Redding, and Schott (2007) delivers a Stolper-Samuelson-like theorem, and as such does not predict that relative factor prices will move in the same direction in both trading countries. Burstein and Vogel (2010) work in a perfect competition framework that has no role for firm heterogeneity, but their elegant treatment of skill-biased technology and its interaction with factor proportions offers an explanation for the rising skill premium in North and South that is similar to our explanation.

Two other closely related papers are Yeaple (2005) and Vannoorenberghe (2011). These two models of firm heterogeneity and trade feature skilled and unskilled workers, and find that trade liberalization raises the relative demand for skill and thus the skill premium. The mechanism in Yeaple (2005) operates purely within firms, and thus rules out the empirically important between-firm compositional effects that we study. Most importantly, both Yeaple (2005) and Vannoorenberghe (2011) analyze trade between identical countries only, and thus does not address the effects of factor endowment differences that are a key feature of our model and of the global economy.

Models in the Heckscher-Ohlin tradition connect preferences to production technology, in the sense that the elasticity of substitution in demand is greater within goods of the same factor intensity. For example, in the canonical $2 \times 2 \times 2$ model, goods with the same factor intensity are homogeneous and therefore have an infinite elasticity of substitution across "varieties". We depart from this tradition, instead treating goods symmetrically in demand, so that the elasticity of substitution in demand is independent of the skill intensity of goods' production. This is an intuitive assumption (why should preferences and production technology be related a priori?) which has striking implications. In particular, it implies that changes in import competition affect all import-competing firms symmetrically. This contrasts with the Stolper-Samuelson mechanism that is a feature of all Heckscher-Ohlin models, where the factor content of imports changes relative demands for import competing goods. In our model the connection between trade liberalization and factor prices operates through an entirely different channel.

Our model treats each firm's production technology as fixed, with the factor market effects of trade 
liberalization due to a composition effect: high-skill firms gain market share globally at the expense of less skill-intensive firms. A complementary mechanism, which is not incorporated in our model, is that highly productive firms increase their skill intensity when faced with new export opportunities. This channel has been studied in a partial equilibrium framework by Bustos (2011), who finds that Argentinian exporters invested in skill-upgrading in response to liberalized trade with Brazil, with liberalization leading to about a two percentage point increase in the skill share for big relative to small firms. ${ }^{3}$ Verhoogen (2008) finds that peso devaluation raised within-plant wage inequality in Mexican manufacturing, and that this effect was stronger for initially more productive firms. Verhoogen (2008) plausibly interprets this result as support for within-plant quality and skill upgrading. A closely related general equilibrium theory of exporters endogenously adopting more skilled technologies is developed by Yeaple (2005). As noted above, however, Yeaple's model only considers trade between identical countries, and thus does not address the interactions between technology, trade and factor endowment differences that are our concern.

Other empirical studies have failed to find large effects of trade liberalization on firm-level or plant-level skill upgrading. In their influential early work, Bernard and Jensen (1997) and Bernard and Jensen (1999) find that the export-related skill-upgrading of U.S. manufacturing was predominantly due to employment shifts that favor skill-intensive plants, rather than differentially rapid skill-upgrading by exporters. Similarly, Trefler (2004) finds that more skilled Canadian manufacturing plants expanded their relative employment shares after trade liberalization with the United States, but did not engage in skill upgrading. We show below that more skilled Chilean manufacturing plants are more likely to be exporters, but their skill intensity is not affected by the export decision. This empirical evidence for the United States, Canada, and Chile is consistent with the mechanism in our model. Incorporating the partial equilibrium theoretical insights of Bustos (2011) and Verhoogen (2008) into our general equilibrium framework would render our model intractable, so we focus exclusively in what follows on between-firm rather than within-firm effects of trade liberalization on relative skill demand. It is clear that within-firm skill upgrading in response to trade liberalization will have effects on the equilibrium skill premium that are complementary to the channel we analyze.

\section{THEORY}

In the Melitz model, there is one factor of production, and firms are identical up to a Hicks neutral productivity parameter $\varphi$ that shifts marginal cost. In an important paper, Bernard, Redding, and Schott (2007) combine the Melitz model with the classic $2 \times 2 \times 2$ Heckscher-Ohlin-Samuelson model, which yields rich interactions between firm heterogeneity and factor proportions differences across sectors and countries. Our model takes a different approach to combining firm heterogeneity with factor proportions differences: we assume that firms differ continuously in two dimensions, productivity and skill intensity. Just as Melitz' assumption of heterogeneous firm productivity was motivated by the evidence, our assumption of heterogeneity in skill intensity is motivated by the fact that skill intensity varies at least as much within conventionallydefined industries as it does between. Dunne, Foster, Haltiwanger, and Troske (2004) find this for the United States (see their Figure 1), and we find it in our Chilean firm dataset (see below).

In incorporating a continuum of skill intensities we depart from the assumption, common to the entire Heckscher-Ohlin tradition in trade theory, that the elasticity of substitution in demand is higher between varieties produced with a common factor intensity than it is between goods produced with different factor intensities. Instead, we assume that the elasticity of substitution between all goods is the same. This implies that there are no Stolper-Samuelson effects because import competition affects all domestic firms equally.

In this section, we first develop the basic structure of our model, and then analyze equilibrium in two cases. The first case considers trade between two identical countries, and the second introduces differences in aggregate factor endowment across countries.

\subsection{Skill biased heterogeneous firms}

As in Melitz (2003), firms in our model must incur a sunk cost before discovering their variable cost function. Production requires both skilled and unskilled labor, which are paid $s$ and $w$ respectively. We

\footnotetext{
${ }^{3}$ We refer here to the author's discussion in the first paragraph of section 4.2.2 of Bustos (2011).
} 
assume that variable cost functions are Cobb-Douglas and differ in two dimensions, the skill share in marginal cost $\alpha$ and productivity in marginal $\operatorname{cost} \varphi$,

$$
c_{v}(\alpha, \varphi, s, w)=s^{\alpha} w^{1-\alpha} \varphi^{-1} .
$$

Applying Shepard's Lemma, it follows that skilled labor demand in variable cost per unit output is

$$
h_{v}\left(\alpha, \varphi, \frac{s}{w}\right)=\alpha\left(\frac{s}{w}\right)^{\alpha-1} \varphi^{-1}
$$

Similarly, unskilled labor demand in variable cost per unit output is

$$
l_{v}\left(\alpha, \varphi, \frac{s}{w}\right)=(1-\alpha)\left(\frac{s}{w}\right)^{\alpha} \varphi^{-1}
$$

Because $\varphi$ is a Hicks-neutral productivity shifter, factor intensity in variable cost does not depend on productivity,

$$
\frac{h}{l}\left(\alpha, \frac{s}{w}\right)=\frac{\alpha}{1-\alpha}\left(\frac{w}{s}\right)
$$

Inverse marginal cost, which we will refer to as "competitiveness" is

$$
\phi(\alpha, \varphi, s, w)=\frac{\varphi}{s^{\alpha} w^{1-\alpha}} .
$$

The technology parameters $\alpha$ and $\varphi$ are drawn simultaneously from a joint distribution function $G(\alpha, \varphi)$. As will be seen below, firms that have the same value of $\phi$ but differ in $\alpha$ will be alike in almost every respect (revenue, profitability, export status, etc.) except for their factor demands. Thus, while in Melitz (2003) and Bernard, Redding, and Schott (2007) firms within an industry are indexed only by their productivity $\varphi$, in our model the relevant index will in most settings be competitiveness $\phi^{4}$

There are three fixed cost activities in our model: entry, production for domestic sale, and exporting. While factor intensity in variable costs differ across firms in our model, we assume that factor intensity in fixed costs are common across firms. The fixed cost functions are

$$
\begin{gathered}
c_{f_{e}}(s, w)=\omega(s, w) f_{e} \\
c_{f}(s, w)=\omega(s, w) f \\
c_{f_{x}}(s, w)=\omega(s, w) f_{x},
\end{gathered}
$$

where $f_{e}, f$, and $f_{x}$ denote fixed costs associated with entry, domestic production, and exporting respectively. The factor cost term $\omega(s, w)$ is the same for all firms and fixed cost activities. Furthermore, we assume that the factor intensity of fixed costs is constant, and equal to the economy's overall factor abundance,

$$
\begin{gathered}
\omega(s, w)=\beta s+(1-\beta) w \\
\frac{\beta}{1-\beta}=\frac{H}{L},
\end{gathered}
$$

where $H$ and $L$ are the economy's inelastic aggregate supplies of skilled and unskilled workers respectively. An implication of (8) is that the average wage in fixed cost activities is the economy's average wage. Because we want to restrict the heterogeneity of firms to differences in their variable costs, we assume that $\alpha$ and $\varphi$ do not affect productivity in fixed costs. As will be seen below, the fixed factor proportions assumption neutralizes the effect of variations in entry on aggregate relative factor demands.

\footnotetext{
${ }^{4}$ In the Greek alphabet, the symbols $\phi$ and $\varphi$ are simply different representations of the same letter, pronounced "phi". The reader may find it useful to mentally pronounce the symbol $\phi$ as "phi", and the symbol $\varphi$ as "var-phi".
} 


\subsection{Demand}

Preferences are given by a standard symmetric CES utility function with elasticity of substitution $\sigma>1$. The assumed market structure is monopolistic competition. As is well-known for this setup, firms charge a price $p$ which is a constant markup over marginal cost. Marginal cost is $1 / \phi$ for sales in the domestic market $d$ and $\tau / \phi$ for sales in the export market $x$, where $\tau>1$ is an iceberg transport cost factor, so

$$
\begin{aligned}
p_{d}(\phi) & =\frac{1}{\rho \phi} \\
p_{x}(\phi) & =\frac{\tau}{\rho \phi},
\end{aligned}
$$

where $\rho=\frac{\sigma-1}{\sigma} \in(0,1)$.

Our assumptions on demand imply that consumer preferences over goods have no connection to the factor intensity of goods' production. This is a natural specification, since preferences and production techniques are logically separate concepts, and there is no particular empirical reason to think that they are linked. However, this assumption is in sharp contrast to the Heckscher-Ohlin tradition in trade theory. In the canonical $2 \times 2 \times 2$ model, the two homogeneous goods differ in their factor intensity, there is a finite elasticity of substitution between the goods, and an infinite elasticity of substitution across "varieties" within goods. In their integration of monopolistic competition into the $2 \times 2 \times 2$ model, Helpman and Krugman (1985) maintain this ranking of elasticities of substitution in less extreme form: there is a finite elasticity of substitution $\sigma>1$ across varieties produced with a given factor intensity, and a smaller elasticity of substitution across varieties produced with different factor intensities. The same assumptions on preferences are made by Bernard, Redding, and Schott (2007) and Burstein and Vogel (2010). Like our model, the model of Romalis (2004) features monopolistic competition and Cobb-Douglas production where the factor cost shares vary continuously. Following Dornbusch, Fischer, and Samuelson (1980), Romalis identifies goods with their factor intensity, and assumes that the elasticity of substitution across goods is one while the elasticity across varieties within goods is greater than one. As will become clear in what follows, our decision to break with this Heckscher-Ohlin tradition and sever the link between preferences and production technology has major implications for how factor markets respond to trade liberalization.

\subsection{Equilibrium with identical countries}

In this section, we consider trade between two countries that are identical in every way, including their factor endowments $H$ and $L$ and the distribution $G(\alpha, \varphi)$ from which entering firms draw their technology ${ }^{5}$. Generalizing our analysis to more than two symmetric countries is trivial. Entering firms must pay a fixed $\operatorname{cost} \omega(s, w) f_{e}$ to learn their technology, a fixed cost $\omega(s, w) f$ if they wish to sell in the domestic market, and a fixed cost $\omega(s, w) f_{x}$ if they wish to export. Much of this section is based closely on Melitz (2003), so we move quickly.

\subsubsection{Firm behavior}

With monopolistic competition and CES preferences, firm-level demand depends on aggregate nominal income $R$ and the aggregate price index $P$. Since prices depend only on each firm's competitiveness $\phi$, revenue and sales will differ across two firms if and only if they differ in $\phi$. Standard computations show that the associated sales revenue $r$ and profits $\pi$ from domestic sales $d$ and exporting $x$ are

$$
\begin{gathered}
r_{d}(\phi)=R(\rho P)^{\sigma-1} \phi^{\sigma-1} \\
r_{x}(\phi)=\tau^{1-\sigma} r_{d}(\phi) \\
\pi_{d}(\phi)=\frac{r_{d}(\phi)}{\sigma}-\omega(s, w) f \\
\pi_{x}(\phi)=\frac{r_{x}(\phi)}{\sigma}-\omega(s, w) f_{x} .
\end{gathered}
$$

\footnotetext{
${ }^{5}$ We assume that $G(\alpha, \varphi)$ is twice continuously differentiable over its support $[0,1] \times \mathbb{R}_{+}^{1}$.
} 
Note that we have defined $\pi_{x}(\phi)$ as the profit from exporting only. If a firm sells in both export and domestic markets, then its aggregate profits will be $\pi_{d}(\phi)+\pi_{x}(\phi)$.

Firms will sell in a market only if profits from doing so are non-negative. Thus, equations (14) and (15) implicitly define the minimum levels of $\phi$ for which firms will choose to sell at home and abroad,

$$
\begin{gathered}
r_{d}\left(\phi^{*}\right)=\sigma \omega(s, w) f \\
r_{x}\left(\phi_{x}^{*}\right)=\sigma \omega(s, w) f_{x} .
\end{gathered}
$$

Dividing (17) by (16) and substituting using (12) and (13) implies

$$
\phi_{x}^{*}=\phi^{*} \tau\left(\frac{f_{x}}{f}\right)^{\frac{1}{\sigma-1}}
$$

As long as $\tau\left(f_{x} / f\right)^{\frac{1}{\sigma-1}}>1$, then $\phi_{x}^{*}>\phi^{*}$. This implies that all exporting firms will also sell domestically and the highest cost surviving firms will not export. We will maintain this realistic parameter restriction in all of what follows.

The cutoffs $\phi^{*}$ and $\phi_{x}^{*}$ define regions in the $(\alpha, \varphi)$ space,

$$
\begin{gathered}
D\left(\phi^{*}, s, w\right)=\left\{(\alpha, \varphi) \in[0,1] \times \mathbb{R}_{+}^{1}: \phi^{*} \leq \frac{\varphi}{s^{\alpha} w^{1-\alpha}}\right\} \\
X\left(\phi_{x}^{*}, s, w\right)=\left\{(\alpha, \varphi) \in[0,1] \times \mathbb{R}_{+}^{1}: \phi_{x}^{*} \leq \frac{\varphi}{s^{\alpha} w^{1-\alpha}}\right\} .
\end{gathered}
$$

All firms with $(\alpha, \varphi) \in D$ are active in equilibrium while firms with $(\alpha, \varphi) \in X$ are also exporters, where $X \subset D$. These regions are illustrated in Figure 1. After paying the entry fixed cost and before discovering its' technology, the ex ante probability that a potential firm is active and/or an exporter is the probability that it draws a technology $(\alpha, \varphi)$ in $D$ or $X$ respectively,

$$
\begin{gathered}
\chi_{d}=\operatorname{Pr}[(\alpha, \varphi) \in D]=\iint_{(\alpha, \varphi) \in D} g(\alpha, \varphi) d \alpha d \varphi \\
\chi_{x}=\operatorname{Pr}[(\alpha, \varphi) \in X]=\iint_{(\alpha, \varphi) \in X} g(\alpha, \varphi) d \alpha d \varphi,
\end{gathered}
$$

where $g(\alpha, \varphi)=\partial^{2} G / \partial \alpha \partial \varphi$ is the joint density associated with $G(\alpha, \varphi)$. Conditional on selling domestically, the probability of being an exporter is $\chi=\chi_{x} / \chi_{d}<1$.

\subsubsection{Free entry}

There is an unbounded mass of risk-neutral potential entrants. Free entry implies that in equilibrium the expected value of entry is equal to the fixed entry cost. To develop this free entry condition, we follow Bernard, Redding, and Schott (2007), who simplify the treatment of free entry in Melitz (2003).

The weighted average competitiveness of all active firms and exporters respectively are

$$
\begin{aligned}
\tilde{\phi}\left(\phi^{*}\right) & =\left[\chi_{d}^{-1} \iint_{(\alpha, \varphi) \in D} \phi(\alpha, \varphi)^{\sigma-1} g(\alpha, \varphi) d \alpha d \varphi\right]^{\frac{1}{\sigma-1}} \\
\tilde{\phi}_{x}\left(\phi_{x}^{*}\right) & =\left[\chi_{x}^{-1} \iint_{(\alpha, \varphi) \in X} \phi(\alpha, \varphi)^{\sigma-1} g(\alpha, \varphi) d \alpha d \varphi\right]^{\frac{1}{\sigma-1}} .
\end{aligned}
$$

The average firm will make variable profits $\pi_{d}(\tilde{\phi})$, while the average exporter will make additional variable profits $\pi_{x}\left(\tilde{\phi}_{x}\right)$. Thus, the expected profit conditional on entry is 


$$
\bar{\pi}=\pi_{d}(\tilde{\phi})+\chi \pi_{x}\left(\tilde{\phi}_{x}\right) .
$$

The average entrant will earn $\bar{\pi}$ until death, which arrives at rate $\delta$. With no discounting, the expected value of entry is then $\chi_{d} \bar{\pi} / \delta$, so the free entry condition is

$$
\frac{\bar{\pi}}{\delta} \chi_{d}=\omega(s, w) f_{e} .
$$

Using the cutoff conditions (16) and (17) together with the fact that $r_{d}\left(\phi^{\prime}\right)=r_{d}(\phi)\left(\phi^{\prime} / \phi\right)^{\sigma-1}$ and the definitions of profit, the free entry condition (26) can be rewritten as

$$
\begin{gathered}
f \iint_{(\alpha, \varphi) \in D}\left[\left(\frac{\phi(\alpha, \varphi)}{\phi^{*}}\right)^{\sigma-1}-1\right] g(\alpha, \varphi) d \alpha d \varphi+ \\
f_{x} \iint_{(\alpha, \varphi) \in X}\left[\left(\frac{\phi(\alpha, \varphi)}{\phi_{x}^{*}}\right)^{\sigma-1}-1\right] g(\alpha, \varphi) d \alpha d \varphi=\delta f_{e} .
\end{gathered}
$$

Although the factor cost terms $\omega(s, w)$ associated with the fixed costs do not appear in (27), factor prices do enter the equation because they help determine the boundaries of the sets $D$ and $X$. Thus, unlike Bernard, Redding, and Schott (2007), it is necessary to solve for factor prices jointly with the cutoff $\phi^{*}$.

\subsubsection{Labor Market Equilibrium}

The labor market equilibrium conditions in our model are quite different from the corresponding conditions in Melitz (2003) and Bernard, Redding, and Schott (2007). The reason is that in our model, each firm's demand for skilled and unskilled labor depends on its technology draw $(\alpha, \varphi)$ as well as factor prices. In particular, two firms that have the same level of $\phi$, and thus the same prices, revenues, etc. may have different demands for labor.

From the expressions for inverse marginal cost, prices and revenue (equations 4, 10, 11, 12, and 13), we obtain total output for domestic sale and for export,

$$
\begin{gathered}
q_{d}(\alpha, \varphi)=R(P)^{\sigma-1}\left(\frac{\rho \varphi}{s^{\alpha} w^{1-\alpha}}\right)^{\sigma} \\
q_{x}(\alpha, \varphi)=\tau^{1-\sigma} q_{d}(\alpha, \varphi) .
\end{gathered}
$$

Using (2) and (3) with (28) and (29), we can express each firm's demand for skilled and unskilled labor in variable cost. Labor demand per firm for domestic sales is, $\forall(\alpha, \varphi) \in D$,

$$
\begin{aligned}
H_{d v}(\alpha, \varphi, s, w) & =\rho^{\sigma} R P^{\sigma-1} \alpha s^{(1-\sigma) \alpha-1} w^{(1-\sigma)(1-\alpha)} \varphi^{\sigma-1} \\
& =\rho^{\sigma} R P^{\sigma-1} \times \tilde{H}_{d v}(\alpha, \varphi, s, w) \\
L_{d v}(\alpha, \varphi, s, w) & =\rho^{\sigma} R P^{\sigma-1}(1-\alpha) s^{(1-\sigma) \alpha} w^{\sigma(\alpha-1)-\alpha} \varphi^{\sigma-1} \\
& =\rho^{\sigma} R P^{\sigma-1} \times \tilde{L}_{d v}(\alpha, \varphi, s, w) .
\end{aligned}
$$

We have written labor demand per firm as the product of two terms, one which depends on the aggregates $R P^{\sigma-1}$ and one which depends on the firms technology $(\alpha, \varphi)$. Labor demand per firm for export sales is, $\forall(\alpha, \varphi) \in X$, a fraction $\tau^{1-\sigma}$ of domestic sales,

$$
\begin{gathered}
H_{x v}(\alpha, \varphi, s, w)=\tau^{1-\sigma} H_{d v}(\alpha, \varphi, s, w) \\
L_{x v}(\alpha, \varphi, s, w)=\tau^{1-\sigma} L_{d v}(\alpha, \varphi, s, w) .
\end{gathered}
$$

Total labor demand for exporters is the sum of labor used for domestic and export sales.

The mass of firms in the economy in equilibrium is $M$, and the mass of exporters is $M_{x}=\chi M$. To compute aggregate labor demand in variable cost we integrate over the per-firm labor demands for all active firms, and multiply by the mass of firms. ${ }^{6}$ This gives aggregate labor demand

\footnotetext{
${ }^{6}$ The densities for domestic and exporting firms equal $g(\alpha, \varphi)$ divided by the probablities $\chi_{d}$ and $\chi_{x}$ respectively.
} 


$$
\begin{gathered}
H_{v}\left(s, w, \phi^{*}\right)=\chi_{d}^{-1} M \rho^{\sigma} R P^{\sigma-1} \times \\
{\left[\iint_{\alpha, \varphi) \in D} \tilde{H}_{d v} g(\alpha, \varphi) d \alpha d \varphi+\tau^{1-\sigma} \iint_{(\alpha, \varphi) \in X} \tilde{H}_{d v} g(\alpha, \varphi) d \alpha d \varphi\right]} \\
L_{v}\left(s, w, \phi^{*}\right)=\chi_{d}^{-1} M \rho^{\sigma} R P^{\sigma-1} \times \\
{\left[\int_{\alpha, \varphi) \in D} \tilde{L}_{d v} g(\alpha, \varphi) d \alpha d \varphi+\tau^{1-\sigma} \iint_{(\alpha, \varphi) \in X} \tilde{L}_{d v} g(\alpha, \varphi) d \alpha d \varphi\right] .}
\end{gathered}
$$

Dividing (34) by (35) gives aggregate relative skill demand in variable cost,

$$
\frac{H_{v}\left(s, w, \phi^{*}\right)}{L_{v}\left(s, w, \phi^{*}\right)}=\frac{\iint_{(\alpha, \varphi) \in D} \tilde{H}_{d v} g(\alpha, \varphi) d \alpha d \varphi+\tau^{1-\sigma} \iint_{(\alpha, \varphi) \in X} \tilde{H}_{d v} g(\alpha, \varphi) d \alpha d \varphi}{\iint_{(\alpha, \varphi) \in D} \tilde{L}_{d v} g(\alpha, \varphi) d \alpha d \varphi+\tau^{1-\sigma} \iint_{(\alpha, \varphi) \in X} \tilde{L}_{d v} g(\alpha, \varphi) d \alpha d \varphi} .
$$

Next we develop aggregate labor demand in fixed cost activities. Let the number of prospective new firms at each moment be $M_{e}$, of whom a fraction $\chi_{d}$ will produce after discovering their technology. In steady state equilibrium, the number of new firms per unit time equals the number of dying firms, $\chi_{d} M_{e}=\delta M$. Thus for each active firm, there are $\delta / \chi_{d}$ entrants, of whom a fraction $\chi$ are also exporters. Using (5), (6), and (7) gives total fixed costs per active firm $^{7}$

$$
[\beta s+(1-\beta) w]\left[\frac{\delta f_{e}}{\chi_{d}}+f+\chi f_{x}\right] .
$$

By Shepard's lemma, skilled and unskilled labor demand in fixed cost activities are

$$
\begin{gathered}
H_{f}=M \beta\left[\frac{\delta f_{e}}{\chi_{d}}+f+\chi f_{x}\right] \\
L_{f}=M(1-\beta)\left[\frac{\delta f_{e}}{\chi_{d}}+f+\chi f_{x}\right] .
\end{gathered}
$$

Dividing (38) by (39) gives aggregate relative skill demand in fixed cost activities as

$$
\frac{H_{f}}{L_{f}}=\frac{\beta}{1-\beta} .
$$

By our parameterization of $\beta$ in (9), it immediately follows that $H_{f} / L_{f}=H / L$. Thus variations in the level of fixed cost activities do not affect the aggregate relative skill supply available for variable cost production. This allows us to state the relative labor market clearing condition using (36) as

$$
\frac{H_{v}\left(s, w, \phi^{*}\right)}{L_{v}\left(s, w, \phi^{*}\right)}=\frac{H}{L} .
$$

At this point we choose the unskilled wage $w$ as our numeraire, $w=1$, so $s$ is the skill premium. ${ }^{8}$ The relative labor market clearing condition (41) and the free entry condition (27) constitute a two equation system in two endogenous variables, $s$ and $\phi^{*}$. As will be seen in the next section, all the rest of the endogenous variables in the model are functions of $\phi^{*}$ and $s$, so equations (27) and (41) are the key equations for solving the symmetric country version of our model.

\footnotetext{
${ }^{7}$ See Baldwin (2005) for more on this treatment of fixed costs in the Melitz model.

${ }^{8}$ To ensure that $s \geq 1$, we assume that skilled workers can work as unskilled workers if they choose, but not vice versa.
} 


\subsubsection{Aggregation and equilibrium}

To close the model we need to determine the aggregates $M, R$ and $P$. Although $w$ is our numeraire, we continue to write it out explicitly in what follows for clarity and to prepare for the analysis of the model with factor endowment differences in the next section.

As in Melitz (2003), the free entry condition implies that profits equal the expenditure on fixed costs, which in turn is paid to labor. Thus all revenue goes to labor, so

$$
R=s H+w L .
$$

Revenue of the average firm is related to the profit of the average firm by $\bar{\pi}=\bar{r} / \sigma-\omega(s, w)(f+\chi f)$. Substituting from the free entry condition (26) gives

$$
\bar{r}=\sigma \omega(s, w)\left(f+\chi f+\frac{\delta f_{e}}{\chi_{d}}\right) .
$$

This allows us to determine the mass of firms, ${ }^{9}$

$$
M=\frac{R}{\bar{r}}=\frac{H+L}{\sigma\left(f+\chi f_{x}+\frac{\delta f_{e}}{\chi_{d}}\right)} .
$$

The price index comes from the CES utility function, and depends on the prices of domestically produced and imported goods. Using the pricing equations (10) and (11) in the standard formula for the CES price index gives

$$
P=\left[M\left(\rho \tilde{\phi}_{d}\right)^{\sigma-1}+\chi M\left(\frac{\rho}{\tau} \tilde{\phi}_{x}\right)^{\sigma-1}\right]^{\frac{1}{1-\sigma}} .
$$

This completes the description of the model in the case of identical countries. Equations (27) and (41) solve for $\phi^{*}$ and $s$. Equation (18) then determines $\phi_{x}^{*}$, which allows computation of $\tilde{\phi}_{d}$ and $\tilde{\phi}_{x}$ using (23) and (24). The aggregates $R, M$, and $P$ can then be computed using equations (42), (44), and (45). All firm level variables are functions of $s, R$, and $P$.

\subsubsection{Trade liberalization and the skill premium}

In our model, as in Melitz (2003), exporters are low cost firms. In the data, a common finding is that exporters are more skill intensive than non-exporting firms, even within industries. We will present data below that illustrates the skill bias of exporters for Chile, and the same is true for the United States (see for example Table 3 in Bernard, Jensen, Redding, and Schott (2007)). In this section we show the factor market consequences of trade liberalization in the empirically relevant case of skill-biased technology. We also analyze the case where there is no relationship between technology and skill intensity.,

Skill biased technology. If the skill premium is positive $(s / w>1)$, then skill intensive firms will have higher costs, controlling for productivity $\varphi$. Therefore, in our model the only way for exporters to be more skill-intensive than the average is if skill intensity $\alpha$ and productivity $\varphi$ are positively correlated when firms draw their technology parameters. In such a case, high skill intensity is on average associated with high competitiveness $\phi$. For now we simply assume such a correlation in the ex ante technology distribution $G(\alpha, \varphi)$, and we will calibrate the correlation in the numerical analysis below.

What does our model imply about the labor market effects of opening to trade? Holding factor prices fixed for the moment, our model works exactly like Melitz (2003): opening to trade reduces revenue in the domestic market because of import competition, and creates opportunities for extra revenue in the export market. In the new equilibrium, the survival cutoff $\phi^{*}$ rises, and with costly trade the export cutoff $\phi_{x}^{*}$ is higher than $\phi^{*}$. For new exporters, labor demand rises, while for non-exporters labor demand falls. By our assumption on $G(\alpha, \varphi)$, the exporting firms are more skill intensive on average than the non-exporting firms, so the expansion of the former and the contraction of the latter means a shift up in the relative demand for

\footnotetext{
${ }^{9}$ Here we use $\omega(s, w)=\frac{s H+w L}{H+L}$ to simplify.
} 
skill, equation (36). To satisfy the relative labor market clearing condition (41), the skill premium must rise. We thus have

Proposition 1. Opening to trade between identical countries with skill-biased heterogeneous firms leads to a increase in the skill premium in both countries.

Proof: See Appendix 1.

The effects on the sets of surviving and exporting firms are illustrated in Figure 2.

The result that trade liberalization may raise the skill premium appears in other models, as noted in our introduction. What is new in our model is the integration of relative labor demand effects with firm heterogeneity, as well as the ability of the model to match key moments in the data (see Section 3 below). ${ }^{10}$ Our model predicts that exporters are both more skill-intensive and more productive than non-exporters, and it is this interaction that generates the increased skill premium with trade liberalization.

There are aggregate welfare gains from opening to trade in our model, but the factor price effects leave open the possibility that unskilled workers may see real wage losses from opening to trade. We investigate this issue in our numerical analysis below.

No skill bias in technology. We now consider the case where the skill share $\alpha$ and productivity $\varphi$ are independent, so that the the ex ante technology distribution can be written as the product of the marginal distributions, $G(\alpha, \varphi)=G_{\alpha}(\alpha) G_{\varphi}(\varphi)$. There are no analytical results for this case in general. However, if the distribution of $\varphi$ is Pareto and the distribution of $\alpha$ is uniform, we show in Appendix 1 that trade liberalization increases the survival cutoff for competitiveness $\phi^{*}$ and reduces the export cutoff $\phi_{x}^{*}$ but has has no effect on the skill premium. The intuition for this result is straightforward: opening to trade has the standard pro-competitive effects, but the resulting changes in firm-level relative labor demand are not biased in favor of either skilled or unskilled labor. We also show that relative factor prices depend only on relative factor endowments. We collect these results in

Proposition 2. When skill intensity $\alpha$ and productivity $\varphi$ are independent, with $\varphi$ distributed Pareto and $\alpha$ distributed uniform, and countries are identical, relative factor prices depend only on relative factor endowments. Trade liberalization raises the survival cutoff $\phi^{*}$ and reduces the export cutoff $\phi_{x}^{*}$ and has no effect on the skill premium.

Proof: See Appendix 1.

Though Proposition 2 only holds for particular choices for the distributions of $\alpha$ and productivity $\varphi$, in our numerical analysis below we show that trade liberalization between identical countries with no skill bias in technology has very close to zero effect on the skill premium. Propositions 1 and 2 together illustrate the point that it is skill-bias in technology which leads to factor market effects of trade liberalization in our model.

\subsection{Equilibrium with factor endowment differences}

In this section we extend our model to consider trade between countries that differ in their relative factor endowments. We continue to assume that countries have the same cost functions and ex ante technology distributions $G(\alpha, \varphi)$. This is an interesting and relevant case, and the basic logic of the model is very similar to the identical country case. However the need to keep track of two countries (who we denote by $A$ and $B$ superscripts) complicates the notation considerably. Where possible we closely follow Bernard, Redding, and Schott (2007), who develop an elegant approach to analyzing non-identical countries in a Melitz-style model.

\footnotetext{
${ }^{10}$ Vannoorenberghe (2011) gets the same result in a simpler model, with one-dimensional firm heterogeneity and no free entry of firms. Vannoorenberghe (2011) does not move beyond the symmetric country case, however, which we do next.
} 


\subsubsection{Firm behavior and the entry and export cutoffs}

Domestic revenue for a firm in country $c$ depends only on the macro variables $R^{c}\left(P^{c}\right)^{\sigma-1}$ and inverse marginal cost,

$$
r_{d}^{c}(\phi)=R^{c}\left(\rho P^{c}\right)^{\sigma-1} \phi^{\sigma-1} .
$$

Variable profits from domestic sales are a fraction $1 / \sigma$ of revenues, from which we subtract fixed costs to get profits in the domestic market, which defines the zero profit cutoff level of inverse marginal cost,

$$
\begin{gathered}
\pi_{d}^{c}(\phi)=\frac{r_{d}^{c}(\phi)}{\sigma}-\omega\left(s^{c}, w^{c}\right) f \\
r_{d}^{c}\left(\phi^{* c}\right)=\sigma \omega\left(s^{c}, w^{c}\right) f .
\end{gathered}
$$

Export revenue may differ from domestic market revenue for two reasons: transport $\operatorname{costs} \tau$ and differences in $R^{c}\left(P^{c}\right)^{\sigma-1}$. Relative revenue in the home and export markets for firms located in the two countries are

$$
\begin{aligned}
& r_{x}^{A}(\phi)=\tau^{1-\sigma}\left(\frac{P^{B}}{P^{A}}\right)^{\sigma-1}\left(\frac{R^{B}}{R^{A}}\right) r_{d}^{A}(\phi)=\Upsilon^{A} r_{d}^{A}(\phi) \\
& r_{x}^{B}(\phi)=\tau^{1-\sigma}\left(\frac{P^{A}}{P^{B}}\right)^{\sigma-1}\left(\frac{R^{A}}{R^{B}}\right) r_{d}^{B}(\phi)=\Upsilon^{B} r_{d}^{B}(\phi),
\end{aligned}
$$

where $r_{x}^{c}$ is export revenue for a firm located in $c$. The variable $\Upsilon^{c}$ is the relative size of $c$ 's export market compared to $c$ 's domestic market. This then defines the incremental profits from exporting and the export productivity cutoff,

$$
\begin{gathered}
\pi_{x}^{c}(\phi)=\frac{r_{x}^{c}(\phi)}{\sigma}-\omega\left(s^{c}, w^{c}\right) f_{x} \\
r_{x}^{c}\left(\phi_{x}^{* c}\right)=\sigma \omega\left(s^{c}, w^{c}\right) f_{x} .
\end{gathered}
$$

By relating the levels of domestic revenue at $\phi^{* c}$ and $\phi_{x}^{* c}$, we can link the export cutoffs to the domestic cutoffs. A bit of algebra establishes

$$
\begin{aligned}
& \phi_{x}^{* A}=\tau\left(\frac{P^{A}}{P^{B}}\right)\left(\frac{R^{A}}{R^{B}} \frac{f_{x}}{f}\right)^{\frac{1}{\sigma-1}} \phi^{* A}=\Lambda^{A} \phi^{* A} \\
& \phi_{x}^{* B}=\tau\left(\frac{P^{B}}{P^{A}}\right)\left(\frac{R^{B}}{R^{A}} \frac{f_{x}}{f}\right)^{\frac{1}{\sigma-1}} \phi^{* B}=\Lambda^{B} \phi^{* B} .
\end{aligned}
$$

It is instructive to compare these expressions to equation (18). Unlike in the identical country case, the endogenous variables $R^{c}$ and $P^{c}$ enter the relationship between $\phi^{* c}$ and $\phi_{x}^{* c}$, so we can not ensure $\phi^{* c}<\phi_{x}^{* c}$ simply by a choice of parameters. Nonetheless, since exporters are generally found to be larger and more productive than non-exporters in the data, we will focus exclusively on equilibria where $\Lambda^{c} \geq 1$.

The cutoffs define regions of active and exporting firms as in equations (19) and (20), with $c$ superscripts as appropriate. The same is true for the definitions of entry and export probabilities given by (21) and (22).

\subsubsection{Free entry}

The free entry condition in each country is virtually the same as in the identical country case. With appropriate $c$ superscripts, the competitiveness averages $\widetilde{\phi}^{c}$ and $\widetilde{\phi}_{x}^{c}$ are defined as in equations (23) and (24), and the free entry conditions are given by (27). A complication relative to the identical country case is that the the aggregates $R^{c}$ and $P^{c}$ enter the free entry conditions, through equations (53) and (54). 


\subsubsection{Labor market equilibrium}

In our development of the relative labor market clearing condition (41) in the identical country case, it was convenient that the aggregates $R^{c}$ and $P^{c}$ cancelled out when forming (41). This is no longer the case because of asymmetries in market sizes. In most instances the correct expressions can be obtained by replacing $\tau^{1-\sigma}$ with $\Upsilon^{c}$.

With appropriate country superscripts on $s, w, P$, and $R$, the equations relevant for labor market equilibrium are changed only slightly. Physical output for sale in the domestic market is as given by equation (28). Output for the export market is given by equation (29), except that $\tau^{1-\sigma}$ is replaced by $\Upsilon^{c}$. The firm-level labor demand equations (30) and (31) are the same as before. Equations (32), (33), (34) and (35) are the same except that $\tau^{1-\sigma}$ is replaced by $\Upsilon^{c}$. Because $\Upsilon^{c}$ now enters each aggregate labor demand equation, terms involving the aggregate variables $R^{c}$ and $P^{c}$ no longer cancel when dividing (34) by (35). The significance of this is that it is no longer possible to solve for factor prices separately from the aggregates $R^{c}$ and $P^{c}$. Instead, factor market equilibrium requires setting labor demand in variable cost equal to labor supply minus labor used in fixed costs:

$$
\begin{aligned}
& H_{v}^{c}\left(s^{c}, w^{c}, \phi^{* c}\right)=H^{c}-H_{f}^{c} \\
& L_{v}^{c}\left(s^{c}, w^{c}, \phi^{* c}\right)=L^{c}-L_{f}^{c} .
\end{aligned}
$$

The treatment of labor used in fixed costs is unchanged, except that we introduce a technological difference across countries by letting the parameter $\beta^{c}=H^{c} / L^{c}$ be country specific. As in the identical country model, the purpose of this assumption is to neutralize any effects of entry on aggregate relative factor demand.

\subsubsection{Aggregation and equilibrium}

The determination of $R$ and $M$ follow equations (42) and (44), which are unchanged despite differences in factor endowments. For the price indices, we account for differences in $\tilde{\phi}^{c}$ and $\tilde{\phi}_{x}^{c}$, the mass of firms $M^{c}$, and the conditional probability of exporting $\chi^{c}$ across countries,

$$
\begin{aligned}
P^{A} & =\left[M^{A}\left(\rho \tilde{\phi}^{A}\right)^{\sigma-1}+\chi^{B} M^{B}\left(\frac{\rho}{\tau} \tilde{\phi}_{x}^{B}\right)^{\sigma-1}\right]^{\frac{1}{1-\sigma}} \\
P^{B} & =\left[M^{B}\left(\rho \tilde{\phi}^{B}\right)^{\sigma-1}+\chi^{A} M^{A}\left(\frac{\rho}{\tau} \tilde{\phi}_{x}^{A}\right)^{\sigma-1}\right]^{\frac{1}{1-\sigma}} .
\end{aligned}
$$

This completes the description of the model with non-identical countries.

Although the underlying economics of the model is unchanged, solution is more challenging when countries are not identical because all the endogenous variables in both countries need to be solved simultaneously. The economics behind this complexity is that each country's per-firm demand shifter $R^{c}\left(P^{c}\right)^{\sigma-1}$ enters the other country's productivity cutoffs. We sketch our solution method here, with more details in Appendix 2.

Define the following vector of seven equilibrium variables

$$
\mu=\left(s^{A}, w^{B}, s^{B}, \phi^{* A}, \phi^{* B}, P^{A}, P^{B}\right)
$$

where we set $w^{A}=1$ as our numeraire. Given an arbitrary $\mu$, the remaining equilibrium values can be determined as follows. First we determine $R^{c}$ from (42). Then we can determine $\phi_{x}^{* c}$ by (53) and (54). Given all cutoffs and factor prices we compute $\chi_{d}^{c}$ and $\chi^{c}$ using (21) and (22), as well as $\tilde{\phi}^{c}$ and $\tilde{\phi}_{x}^{c}$ using (23) and (24). Then we can compute $M^{c}$ from (44). $\mu$ is indeed an equilibrium if it satisfies seven equations: three factor market clearing conditions (equations (55) and (56) for each country, with one equation discarded as redundant), two free entry conditions (equation (27) for each country), and two price indices (57) and (58). 


\subsubsection{Trade liberalization and the skill premium}

What effects do trade liberalization have in the asymmetric country version of our model? Full analysis can only be done numerically, but some insight can be gained through analytical reasoning. In all of what follows, we assume that country $A$ ("North") is more skill abundant than country $B$ ("South").

Consider the two countries in autarky. If skilled labor is sufficiently scarce, the skill premium will be positive in both countries, and higher in $B$,

$$
\left(\frac{s}{w}\right)^{B}>\left(\frac{s}{w}\right)^{A}>1
$$

We consider two cases. The first is the "no skill bias" case, where $\varphi$ and $\alpha$ are uncorrelated. The second, and empirically relevant, "skill biased" case is where $\varphi$ and $\alpha$ are strongly positively correlated. Skill bias implies that unit costs and skill intensity are negatively correlated.

No skill bias in technology. In the no bias case when (59) holds, in autarky there is a negative average relationship between unit costs and factor intensity, with more skill intensive firms having higher unit costs. In short, having a high skill share is bad news for a firm: it means that they have higher labor costs without, on average, any associated technological advantage.

Now consider an opening to costly trade. Holding factor costs fixed, this will lead to an expansion of the lower-cost firms in both countries, and contraction or exit for higher cost firms. Because the low-cost firms are less skill intensive, this will lead to an increased relative demand for unskilled workers in both countries. So we have

Conjecture 1 If $\varphi$ and $\alpha$ are uncorrelated, and autarky skill premiums satisfy (59), then opening to costly trade leads to a fall in the skill premium in both countries.

We are emphatically no longer in a Heckscher-Ohlin world. The reason is simple: in our model there is no connection between factor intensity and preferences. As a result, an increase in import competition in our model, whatever the skill content of the imported goods, affects demand for all domestically produced goods symmetrically. In models with a Heckscher-Ohlin structure, by contrast, an increase in import competition changes the relative demand for domestically produced goods. Because relative goods demand is directly linked to relative factor demands, Stolper-Samuelson type results follow. In our model the factor price effects of opening to trade have nothing to do with demand and everything to do with supply: since skill-intensive firms have higher costs, opening to trade reduces the relative demand for skilled workers.

Skill biased technology. We now turn to the empirically relevant case, where skill intensity is associated with higher factor costs but also better technology on average. We focus on the case where the technology effect is dominant, so that on average more skill intensive firms have lower unit costs. Now consider an opening to costly trade. Holding factor costs fixed, this will lead to an expansion of the lower-cost firms in both countries, and contraction or exit for higher cost firms. This will lead to an increase in the relative demand for skill in both countries. To restore factor market equilibrium, the skill premium must rise in both countries. We summarize this reasoning as

Conjecture 2 If productivity $\varphi$ and $\alpha$ are strongly positively correlated, then opening to costly trade leads to a rise in the skill premium in both countries.

We demonstrate below that Conjectures 1 and 2 hold in our numerical simulations.

The inisght that opening to trade raises the skill premium globally is similar to what we showed for identical countries in Proposition 1, and the mechanism is the same here. 
Trade patterns. Although the factor price effects of opening to trade in our model are very different from what is found in Heckscher-Ohlin models, the trade patterns are broadly in line with Heckscher-Ohlin predictions, although the mechanism is different. Because the skill premium remains lower in $A$ than in $B$ after liberalization, $A$ will have a comparative advantage in high skilled goods, and production in each country will shift toward comparative advantage goods. In our model, what we mean by comparative advantage is that high-skill exporters are more likely to come from $A$, while low-skill exporters are more likely to come from $B$. The specialization pattern is illustrated in Figure 3, which is drawn on the assumption that the overall level of competition is less intense in $B$ than in $A$ (this is not essential, but it is what we find in our numerical analysis below).

\subsection{Quality competition: an alternative interpretation of the model}

Our model assumes two-dimensional heterogeneity in firms' technology, combined with symmetry in demand. Firms' revenue and profits are indexed by their inverse unit cost $\phi$, and larger firms charge lower prices because they have lower unit costs (see equation 10). A way to summarize this is that in our model (as well as in the models of Melitz (2003), Bernard, Redding, and Schott (2007), and others) firms "compete on cost." This conflicts with evidence amassed by many authors, including Verhoogen (2008) and Baldwin and Harrigan (2011), that exporters more often "compete on quality", with more successful firms actually having higher costs and prices than less successful firms. In this subsection we show that our model can easily be converted into a model of quality competition, with quality being positively correlated with skill intensity. ${ }^{11}$ For readers uninterested in the details, the punchline is simple: none of the implications of our model for trade, gains from trade, or factor prices are affected by rewriting it as a model of quality competition.

Suppose that $\varphi$ is not a parameter of cost but of demand. In particular, let the utility function be

$$
U=\left[\int\left[\varphi(i)^{\frac{1}{\rho}} q(i)\right]^{\rho} d i\right]^{\frac{1}{\rho}}
$$

where the integral is over all possible varieties $i$. For aggregate nominal expenditure $R$, this leads to demand functions of the form

$$
q(i)=R(P)^{\sigma-1}\left(\frac{p(i)}{\varphi(i)^{\frac{1}{\rho}}}\right)^{-\sigma}=R(P)^{\sigma-1} p(i)^{-\sigma} \varphi(i)^{\sigma-1}
$$

where the aggregate price index is

$$
P=\left[\int\left(\frac{p(i)}{\varphi(i)^{\frac{1}{\rho}}}\right)^{1-\sigma} d i\right]^{\frac{1}{1-\sigma}} .
$$

In this framework, $\varphi(i)$ is a demand shifter which we will call "quality", and the price index is a symmetric function of quality-adjusted prices $p(i) / \varphi(i)^{\frac{1}{\rho}}$.

Marginal cost varies across firms because of variation in the skilled labor share $\alpha$, but does not depend on quality $\varphi$,

$$
c_{v}(\alpha, s, w)=s^{\alpha} w^{1-\alpha} .
$$

Pricing is also independent of quality,

$$
p_{d}(\alpha, s, w)=\frac{s^{\alpha} w^{1-\alpha}}{\rho} .
$$

Substituting price into demand and multiplying by price leads to expressions for revenue and profits which are the same as equations (12) through (15). As in our main model, all that matters for revenue and profits is competitiveness. In the main model competitiveness is simply inverse unit cost, while here it is inverse unit cost times quality $\varphi$. The development of the zero profit cutoffs is the same as before, which leads to

\footnotetext{
${ }^{11}$ This correlation is exactly what Kugler and Verhoogen (2010) find for Colombia.
} 
definitions of the regions $D$ and $X$ which are the same as those given by (19) and (20), except that $\varphi$ is replaced by $\varphi^{\frac{1}{\rho}}$. Substituting the definition of competitiveness (4) into (12) gives the following expression for domestic revenue as a function of quality,

$$
r_{d}(\alpha, \varphi, s, w)=R(\rho P)^{\sigma-1}\left(s^{\alpha} w^{1-\alpha}\right)^{1-\sigma} \varphi^{\sigma-1} .
$$

The corresponding expression in the main model is identical.

Expressions for labor demand are also unchanged. Following the same steps as in section 2.3.3 leads to expressions for firm-level labor demand which are identical to equations (30) and (31) above.

We see that in both the main model and the quality-competition variant employment and revenue have the same elasticity with respect to $\varphi$. Thus, anything that affects the revenue distribution (such as a trade liberalization) will have the same effects on labor demand in either model. It is straightforward to close the quality-competition model in exactly the way we proceeded above for the main model.

The final step is to suppose that after paying their sunk entry costs, firms jointly draw their skill intensity and quality from $G(\alpha, \varphi)$. As argued by Kugler and Verhoogen (2010), producing high quality is likely to require a more skilled labor force, which implies that $\operatorname{Cov}(\alpha, \varphi)>0$, just as in the main model. With this assumption, all our results about the labor market effects of trade liberalization go through unchanged.

Our conclusion from this subsection is simple: the quality competition variant of our model of skill biased heterogeneous firms has the same workings and implications as the main model. With this point established, we put aside the quality competition variant for the remainder of the paper.

\section{EMPIRICAL AND NUMERICAL ANALYSIS}

In this section we bring numbers to bear on our model in three ways. First, we examine a plant-level data set from a small open economy, Chile 1990-1995, and show that key features of the Chilean data match the key assumptions of our model. Second, we use the Chilean data in 1995 to calibrate our identical country model. Lastly, we use the numerical version of our model to illustrate its workings, with a focus on the effects of trade liberalization on the skill premium.

\subsection{Chilean plant level data}

Our data source is the Annual National Industrial Survey of Chile (Encuesta Nacional Industrial Annual, or ENIA). ${ }^{12}$ The ENIA is conducted annually by the Chilean government statistical office (Instituto Nacional de Estadistica, or INE). The ENIA covers the universe of Chilean manufacturing plants with 10 or more workers. Pavcnik (2002) indicates that in 1979-1986 more than 90\% of Chilean manufacturing firms had only one plant, so the distinction between plants and firms is unlikely to be very important. Our concept of a skilled worker is captured in the ENIA by white collar workers. ${ }^{13}$ For each of these plants we construct the following variables:

- $\log$ revenue

- export intensity $=$ export revenue $/$ total revenue

- $\log$ average wage

- white collar employment share

- white collar wage bill share

- export status (1 if export revenue $>0$ ).

\footnotetext{
${ }^{12}$ We thank James Tybout for generosly providing us this data.

${ }^{13}$ Proxying skill by "white collar" is problematic, though it is (by necessity) common practice in studies that use plant level data. Berman, Bound, and Griliches (1994) show that for the United States, the production/non-production worker classification is a good proxy for skilled and unskilled workers.
} 
Standard regression-based methods (such as Olley-Pakes) of computing plant-level total factor productivity (TFP) are not applicable here. The reason is simple: regression-based TFP calculations need to assume that factor shares are constant across all plants. This is both empirically false (as we show immediately below) and contradicts the mechanism of our theory. The absence of plant-level TFP is not a drawback for our purposes, as our minimum distance estimator (discussed below) identifies all the necesary parameters using the data moments that we do have.

\subsubsection{The 1995 Chilean plant cross section}

5,112 plants were surveyed in 1995 . We eliminated 163 plants that did not report positive revenues. We also eliminated 346 plants that had either white collar employment share or white collar wage bill share equal to 0 or 1 (these coincide $93 \%$ of the times). These plants account for $5.3 \%$ of total revenue in the sample and are $30 \%$ smaller on average, but their distribution of revenues is not very dissimilar from the rest, so that this elimination does not affect much the overall distribution of revenues. However, only $4.6 \%$ of these plants export, compared to $24.3 \%$ of the other plants.

Thus, we use a cross section of 4,603 plants in 1995, of which $24.3 \%$ are exporters. Table 1 shows that exporting plants are larger and more skill-intensive than non-exporters. The distribution of log revenues for exporters is less skewed to the right, i.e. the largest exporters are closer to their respective mean than the largest firms that do not export. As with log revenues, we see that the distribution of the skill employment and wage bill shares for exporters are less skewed to the right. Figure 4 shows the wage bill shares for white collar workers among exporters and non-exporters. The most interesting aspect of Figure 4 is not the difference in median skill shares (which is well known) but the variability: many exporters have low skill shares, and conversely for non-exporters. In fact, the variation of the skill share within the exporter/nonexporter categories is essentially the same as the overall variation. ${ }^{14}$ Table 2 shows that the correlation between $\log$ revenues and the white collar wage bill share is positive, and slightly more so for exporters. Figure 5 illustrates this relationship, and the variability in this figure motivates the key feature of our model: the positive but imperfect correlation between skill intensity and size. We exploit these differences when choosing parameter values for the joint distribution of skilled labor share and productivity in the model.

In addition, the firm-level skill share varies both within industries and across industries, but the within variation is much larger: between 4-digit ISIC industries, the standard deviation of the skill share is 0.11, while within industries the standard deviation is more than half again as big, at 0.17.

\subsubsection{The 1990-1995 Chilean plant panel}

In principle there are at least two mechanisms that can account for a correlation between export status and skill intensity: skill-intensive plants select into exporting, or exporters choose to become more skill intensive. These mechanisms are not mutually exclusive. In our model we focus on the first mechanism, though as noted in our introduction there is evidence in some data sets for the latter mechanism as well. In this subsection we briefly investigate this question in our Chilean data.

Our tool is a series of very simple panel regressions with plant and year fixed effects, along with indicators of export status:

$$
y_{i t}=\alpha_{i}+\alpha_{t}+\boldsymbol{\beta}^{\prime} \mathbf{x}_{i t}+\varepsilon_{i t},
$$

where $y_{i t}$ is an outcome of interest (log revenue or wage bill share of skilled workers), $\mathbf{x}_{i t}$ is a vector of export participation indicators, and $\varepsilon_{i t}$ is interpreted simply as the prediction error from a linear projection. Estimation is by OLS with standard errors clustered by plant.

Table 3 shows our results. The Panel A tells a simple and utterly unsurprising story: entering into exporting leads to big increases in revenue. Panel B, which investigates within-plant variation in the skill share over time, shows no statistically significant evidence of skill upgrading when plants enter into exporting. We get virtually the same results when the regressand is the skilled employment share. As noted in the introduction, this result is consistent with the evidence for the U.S. (Bernard and Jensen (1997), Bernard and Jensen (1999)) and Canada (Trefler (2004)). Our conclusion from this simple exercise is that the Chilean

\footnotetext{
${ }^{14}$ The overall standard deviation of the skill share is 0.197 . Within exporters the standard deviation is 0.205 , while within non-exporters it is 0.185 . The $R^{2}$ of a regression of the skill share on an indicator for export status is just 0.07 .
} 
plant level data set is a reasonable source of information for calibrating some of the key parameters of our model, and we turn to this next.

\subsection{Modelling the correlation between skill intensity and productivity}

A key innovation in our model is that we allow for positive but imperfect correlation between skill intensity $\alpha$ and productivity $\varphi$. This is motivated by the cross-sectional evidence that is vividly illustrated in Figures 4 and 5. To implement this we first specify the marginal distributions of $\alpha$ and $\varphi$, and then model the correlation between them.

It is standard to model variation in productivity with a Pareto distribution, and we follow this practice here. Since the skill share lies in the unit interval, we model it as following a Beta distribution. These densities are respectively ${ }^{15}$

$$
\begin{gathered}
g_{\varphi}(\varphi)=k \varphi^{-k-1} \\
g_{\alpha}(\alpha)=\frac{\alpha^{a-1}(1-\alpha)^{b-1}}{B(a, b)} .
\end{gathered}
$$

To flexibly allow correlation between $\varphi$ and $\alpha$ while maintaining their marginal distributions, we apply the theory of copulas from mathematical statistics (the standard reference is Nelsen (2006)). ${ }^{16}$ The theory of copulas was first used in international trade theory by Davis and Harrigan (2011), also to accommodate two dimensions of heterogeneity in a Melitz-type model. Letting the marginal distribution functions for $\alpha$ and $\varphi$ be $G_{\alpha}(\alpha)$ and $G_{\varphi}(\varphi)$ respectively, our parameterization of $G(\alpha, \varphi)$ uses the Plackett copula,

$$
\begin{gathered}
G(\alpha, \varphi)=\frac{P-\sqrt{P^{2}-4 G_{\alpha} G_{\varphi}(\theta-1)}}{2(\theta-1)}, \\
P=\left[1+(\theta-1)\left(G_{\alpha}+G_{\varphi}\right)\right],
\end{gathered}
$$

where the parameter $\theta>0, \theta \neq 1$ governs the correlation between $\varphi$ and $\alpha$. For $\theta=1, \varphi$ and $\alpha$ are independent, and $G(\alpha, \varphi)=G_{\alpha} G_{\varphi}$. For $\theta \neq 1$, the correlation between the values of the marginal distribution functions is

$$
\operatorname{Corr}\left(G_{\alpha}, G_{\varphi}\right)=\frac{\theta^{2}-1-2 \theta \log \theta}{(\theta-1)^{2}} .
$$

This correlation has range $(-1,1)$ and is monotonically increasing in $\theta$, with negative correlation when $\theta<1$ and positive correlation when $\theta>1$. There is no expression available for the correlation between $\varphi$ and $\alpha$. In our simulations we use $\theta=11$, which gives $\operatorname{Corr}(\alpha, \log \varphi)=0.48$.

\subsection{Estimation and Calibration}

We use a minimum distance estimator to estimate four distributional parameters:

- $k$ - the Pareto shape coefficient in (60).

- $a, b$ - two parameters of the beta distribution in (61).

- $\theta$ - the Plackett copula association parameter in (62).

We hold constant all other parameters of the model. For comparability with the literature, we use the following parameters that are used by Bernard, Redding, and Schott (2007):

- $\sigma=3.8$ (estimated by Bernard, Eaton, Jensen, and Kortum (2003))

\footnotetext{
${ }^{15}$ For the Pareto distribution, we normalize the lower bound to one. For the Beta distribution, $B(a, b)=\frac{\Gamma(a) \Gamma(b)}{\Gamma(a+b)}$, where $\Gamma($.$) is the gamma function.$

${ }^{16}$ In the simplest case, a copula is a function that binds two marginal distribution functions to create a joint distribution function, with the degree of association between the marginal distributions governed by the parameter of the copula.
} 
- $f_{e}=20$

- $f=f_{x}=1$

- $\delta=0.025$

Changing these parameters affects the estimation results below, but we do not investigate this systematically. The aggregate labor force is set at 100 workers, with skill abundance $H / L$ as in the Chilean data: 0.26 (roughly $20 \%$ are skilled workers).

For the sake of estimating the remaining distributional parameters, we must calibrate the variable trade cost parameter $\tau$ as well. To do this, we exploit the fact that in the symmetric country model export intensity (ratio of export revenue to total revenue) is $\tau^{1-\sigma} /\left(1+\tau^{1-\sigma}\right)$. The average export intensity in the Chilean data for 1995 is roughly 0.28 . Given the parameterization of $\sigma=3.8$, this gives roughly $\tau=1.4$.

Estimation proceeds as follows. Given a guess of parameter values we simulate the model for the symmetric open economy case and calculate a vector of moments, $\pi(k, a, b, \theta)$. We choose $(k, a, b, \theta)$ to minimize

$$
\left[\pi(k, a, b, \theta)-\pi^{d}\right]^{\prime} W\left[\pi(k, a, b, \theta)-\pi^{d}\right]
$$

where $\pi^{d}$ are corresponding moments from the Chilean plant data and $W$ is a weighting matrix. ${ }^{17}$

We use the following moments to estimate these parameters, with the model moments calculated by simulation:

- Overall correlation between log revenues and white collar wage bill share. This moment largely identifies $\theta$.

- The difference between average log revenues for exporters versus non exporters.

- Proportion of exporters. Together with the previous one, this moment identifies $k$. Even though we have a functional relationship between $\phi^{*}$ and $\phi_{x}^{*}$, it does not determine the percent of exporters, which is influenced by how fat the right tail of the Pareto distribution is.

- The 5, 25, 50, 75 and 95 percentiles of the white collar wage bill share distribution, separately for exporters and non exporters (10 separate moments). These moments identify $a$ and $b$, and also help to identify $\theta$.

In order to specify the weighting matrix we make some arbitrary choices: we multiply the deviations from the percent of exporters by four; and we multiply the deviations from the empirical $\alpha$ percentiles by two. These weights are chosen to avoid a large spike in the distribution of $\alpha$ for firms who serve only the domestic market. Since we do not have a priori information about which moment is more important, this seems to be a reasonable choice.

The estimates are

- $k=3.6$

- $a=2, b=3.53$

- $\theta=11$.

These are what we use throughout all numerical exercises, and they imply a correlation of 0.48 between the skilled wage share $\alpha$ and productivity $\varphi$, or 0.6 between $\alpha$ and $\log \varphi$.

One remarkable result is that simulation of the model using the estimates yields distributions of $\log$ revenue and the wage bill share that match the shape of the empirical distributions very closely, in particular Figure 4. Although firms with a high skilled workers wage bill share $\alpha$ have higher factor costs (given a positive skill premium), we see relatively more such exporters versus non exporters. The estimation captures this feature, because it assigns a positive correlation with productivity, $\theta=11$.

\footnotetext{
${ }^{17}$ See Cameron and Trivedi (2005) for the relevant econometric theory. Using simulation to calculate model moments introduces some additional error, in addition to sampling error. This error vanishes with the number of draws used to compute the moments. We use one million draws, so this type of error is likely to be very small. See Stern (1997) for a clear exposition of simulation based estimation.
} 
The estimate $k=3.6$ is not far from what Bernard, Redding, and Schott (2007) use, 3.4, and it obeys $k>\sigma-1$, which is a requirement for convergence of integrals in Pareto-Melitz type models (see e.g. Baldwin (2005)). Although the distribution of $\phi$ is not identically Pareto, it is rather close to Pareto, especially for exporters, i.e. in the upper tail of the $\phi$ distribution. The $\log \phi-\log (\operatorname{rank}(\phi))$ scatter (not reported) is virtually a straight line for all active firms and for exporters. For strictly domestic firms, which have a much smaller (and bounded) range of $\phi$, the influence of variation in $\alpha$ is much more important, and therefore the distribution of $\phi$ for this subset of active firms is far from Pareto: the $\log \phi-\log (\operatorname{rank}(\phi))$ scatter is a curved line.

\subsection{Equilibrium with identical countries}

In this section we simulate the identical country version of our model, using the parameters described above. Both countries have relative skill endowments of $H / L=0.26$, and the exercise lowers variable trade costs from autarky, $\tau=\infty$, to costless trade, $\tau=1 .^{18}$ Results are illustrated in Figure 6 and the first column of panel A of Table 4.

The purely Melitz side of the model is illustrated in the four panels of Figure 6a. Trade liberalization leads to heightened competition, which is manifested in progressively higher survival cost cutoffs and lower export cost cutoffs. The result is less equilibrium entry, and the mass of firms is smaller. Unlike in Melitz (2003), the weighted average productivity of active firms is not a useful summary statistic, since it is unit cost, rather than productivity per se, that determines firm success in our model. Instead, we focus on real GDP (nominal GDP divided by the aggregate price index) as a summary of the economy-wide effects of trade liberalization. As expected, real GDP rises substantially as trade barriers are reduced, with the move from autarky to costless trade raising real GDP by 19 percent.

The novelty in our model comes from the factor market consequences of trade liberalization, which are illustrated in the three panels of Figure 6b. The skill premium rises substantially as trade barriers fall, from 2.84 in autarky to 2.98 for moderate trade $\operatorname{costs}(\tau=1.4)$, an increase of 5 percent. Complete elimination of variable trade costs raises the skill premium by 7.7 percent compared to autarky. Real skilled wages rise by almost ten percent in the move from autarky to moderate trade costs, while unskilled workers see more modest real wage increases of 4 percent. It is notable that all workers share in the gains from trade despite the rise in relative skill demand. The reason for this is the improvement in aggregate efficiency caused by trade liberalization, with high-cost low-skill firms exiting or contracting and low-cost, high-skill firms entering the export market. ${ }^{19}$

The second column of Panel A of Table 4 summarizes how our results differ when we nearly double skill abundance, from 0.26 (the level in our Chilean data set) to 0.5 . The gains from trade are slightly higher, and the increase in the skill premium is much smaller, rising just 3.5 percent in the move from autarky to costless trade. The increase in real wages is 22 percent for skilled workers and 18 percent for unskilled workers. The explanation for this contrast is that skill bias puts a premium on skilled workers when trade is liberalized: when they are much more abundant, the economy as a whole gains more, with the gains from trade more evenly shared between skilled and unskilled workers.

\subsection{Equilibrium with factor endowment differences}

Next we turn to trade liberalization between countries that differ in their factor endowments. The relative factor endowments are $(H / L)^{A}=0.5$ and $(H / L)^{B}=0.1$, and we scale country $B$ 's population so that real GDP is the same in both countries in autarky. These factor abundances are chosen to roughly match the skill abundance of the United States and low-income developing countries respectively, and real GDP in autarky is equalized to neutralize market size effects. In all other respects the two countries are identical, most importantly in their ex ante skill-productivity distributions $G(\alpha, \varphi)$. As in the previous exercise, we lower variable trade costs from $\tau=\infty$ to $\tau=1$. Results are illustrated in Figure 7, and in the

\footnotetext{
${ }^{18}$ We maintain fixed costs for exporting that are equal to the fixed costs of entering the home market throughout. For brevity, we say that trade is "costless" when variable trade costs are zero.

${ }^{19}$ Bernard, Redding, and Schott (2007) find a similar result in their model: the aggregate efficiency effect implies that the scarce factor may gain in real terms from opening to trade. In their quantitative exercise they find that the real return to the scarce factor does indeed increase when trade opens.
} 
final three columns of Panel A of Table 4. In computing the equilibria, we choose global nominal GDP as our numeraire, so nominal values are in units of a common currency.

In this numerical exercise we are not attempting to fully calibrate the model to any particular pair of countries or trade liberalization episode. By abstracting from differences in autarky country size and technology distributions, we isolate the mechanisms which are new to our model, which are the interactions between trade liberalization, factor proportions differences, and skill biased heterogeneous firms. Thus the quantitative results here should be interpreted as plausible numerical examples rather than estimates of the effects of an actual trade liberalization episode. ${ }^{20}$

The four panels of Figure 7a illustrate the expected Melitz-type mechanisms: as trade is liberalized, entry becomes more difficult, the mass of firms falls, and the share of exporters gets monotonically higher. Aggregate gains from trade are shown by rising real GDP in both countries. Country $B$ is a somewhat less competitive market than $A$, which is seen in the higher cost cutoffs for $A$ and the associated higher probability of entry in $B$. The reason for this is an interaction between skill bias and the higher skill premium in $B$ : skill bias implies that the lowest cost firms are the most skill-intensive on average in both countries, but because of the higher skill premium in $B$ the cost advantage for the best firms is smaller in $B$ than in $A$. This difference in the ex ante cost distributions in the two countries is illustrated in Figure 8: $B$ has more low-end and fewer high-end firms than does $A$, in both autarky and costless trade equilibria. Thus high cost firms in $B$ earn more revenue than high cost firms in $A$, which makes survival easier. A flip side to this is that $A$ gains a bit more from trade: trade puts a premium on skill, and $A$ 's greater skill abundance and lower skill premium means it can better take advantage of trade liberalization than can skill-scarce $B$.

The four panels of Figure $7 \mathrm{~b}$ illustrate Conjecture 2: trade liberalization raises the skill premium in both countries, and in our numerical exercise this effect continues all the way to costless trade. As can be seen in Table 4, the increases in the skill premium are fairly modest: in the move from autarky to moderate trade costs of $\tau=1.4$, the skill premium increases by 2.1 percent in $A$ and 5.7 percent in $B$, with increases of 3.5 and 8.5 percent respectively when moving all the way to costless trade. An implication is that our example world economy features relative factor price divergence as trade is liberalized, with the skill premium in $B$ relative to $A$ increasing from 2.30 to 2.41 . This result is very much at odds with the factor price equalization forces in Heckscher-Ohlin models. This factor price divergence result need not hold in all numerical simulations.

While the factor price implications of our model are completely at odds with Heckscher-Ohlin models, our model does feature trade in factor services that is predicted by factor abundance. This is illustrated in Figure 9, which shows that the net factor content of trade increases quite rapidly with falls in variable trade costs. $^{21}$

To illustrate the key importance of skill bias in generating our results, in panel B of Table 4 we report results when there is zero ex ante correlation between skill intensity and productivity. To compute these results, the only change we make is to the copula parameter $\theta$. Differences in factor abundance still generate differences in the skill premium, but the level of the skill premium is much lower than in panel A. Trade liberalization leads to gains from trade which are comparable to the skill-bias case, but relative factor prices are virtually unchanged despite large net trade in factor services (similar to what is seen in Figure 9 but not shown in the interest of space). The skill premium does fall very slightly in each case as trade is liberalized, so our numerical results are consistent with Conjecture 1. This illustrates again the absence of StolperSamuelson forces in our model: when factor intensities are unrelated to preferences, trade liberalization does not raise the skill premium unless there is skill-bias.

As a final exercise, we consider convergence in relative factor endowments. We consider our base case of skill biased technology $(\theta=11)$ and moderate trade costs $(\tau=1.4)$, and both countries have the same population. We begin with $(H / L)^{B}=0.1$, and increase human capital in $B$ until it reaches the level in $A$. Table 5 reports the results. Interestingly, $A$ is essentially indifferent to human capital accumulation in $B$, with tiny increases in real wages and the skill premium. At first glance the tiny effect that human capital accumulation in $B$ has on factor markets in $A$ might seem puzzling, since net trade in factor services are changing quite dramatically. The reason is the absence of Stolper-Samuelson effects in our model: though the

\footnotetext{
${ }^{20}$ The quantitative exercises in Burstein and Vogel (2010) and Bernard, Redding, and Schott (2007), for example, should in our view be interpreted in the same way.

${ }^{21}$ We calculate the factor content of trade as follows. For exports, we use the exporting country's unit factor requirements. For imports, we use the exporting country's factor requirements, deflated by the iceberg transport cost factor $\tau$. This explains why the two panels of Figure 9 are not quite mirror images. When $\tau=1$, the net factor contents sum to zero exactly.
} 
average good imported by $A$ from $B$ is becoming more skill intensive as $B$ develops, this has no direct effect on the relative demand for more and less skill-intensive goods produced in $A$. In contrast, $B$ experiences a precipitous drop in the skill premium as real GDP rises, with real skilled wages falling and more than all of the 28 percent increase in GDP going to unskilled workers. The response in $B$ of the skill premium to factor accumulation is consistent with a long-run labor demand elasticity of about -2 , which is within the range found in the labor economics literature (see for example Autor and Katz (1999)). ${ }^{22}$

\section{CONCLUSION}

In this paper we propose a new model that explains why trade liberalization can be associated with a rising skill premium in both rich and poor countries. Our model has two dimensions in which firms differ, skill intensity and productivity, and our assumption that these two attributes are positively correlated is verified using Chilean firm-level data. Because of this correlation, opening to trade shifts up the relative demand for skilled workers, as low-cost, skill-intensive firms expand to seize new export opportunities and high-cost, low-skill firms contract or exit in the face of greater import competition. In equilibrium, the skill premium rises when trade is liberalized between identical countries. It is possible that less skilled workers will see their real wages fall in such a scenario if their nominal wages fall by more than the reduction in the price level, though this does not occur in our simulations: all workers gain from liberalization even as the skill premium rises.

When countries differ in their relative factor endowments, opening to trade also leads to an increase in the skill premium in both countries, and in our example economy there is relative factor price divergence, with the skill premium rising by more in the skill-scarce country. This result is at odds with the StolperSamuelson theorem, which predicts that trade liberalization should lead to a fall in the skill premium in the skill-abundant country and the opposite in the skill-scarce country. The reason is that our model makes a simple and intuitive departure from one of the key assumptions in the Heckscher-Ohlin tradition: we assume that the elasticity of substitution in demand is common across goods, rather than being higher for goods with the same factor intensity. Although our model has a Heckscher-Ohlin flavor in its focus on the interaction between goods with different factor intensities and countries with different factor endowments, this seemingly small change in assumptions means that the model works quite differently than models in the Heckscher-Ohlin tradition.

Quantitatively, the factor price effects we find are small relative both to the size of gains from trade in our model and to the changes in the skill premium in the United States and around the world. Thus we see our results as consistent with the view that trade liberalization can lead to large welfare gains without being a major contributor to growing wage inequality.

\footnotetext{
${ }^{22}$ We refer here to the parameter $\eta$ in an equation of the form $(H / L)=A \times(s / w)^{\eta}$.
} 


\section{REFERENCES}

Abowd, J., J. Haltiwanger, J. Lane, K. McKinney, and K. Sandusky (2007). Technology and the demand for skill: an analysis of within and between firm differences. Technical report, National Bureau of Economic Research.

Acemoglu, D. (2002). Directed technical change. Review of Economic Studies 69(4), 781-809.

Acemoglu, D. (2003). Patterns of skill premia. Review of Economic Studies 70(2), 199-230.

Autor, D., L. Katz, and M. Kearney (2008). Trends in US wage inequality: Revising the revisionists. The Review of Economics and Statistics 90(2), 300-323.

Autor, D., F. Levy, and R. Murnane (2003). The skill content of recent technological change: An empirical exploration. Quarterly journal of economics 118(4), 1279-1333.

Autor, D. H. and L. F. Katz (1999). Changes in the wage structure and earnings inequality. In J. B. Taylor and M. Woodford (Eds.), Handbook of Labor Economics, Volume 3A. Elsevier Science, North Holland.

Baldwin, R. (2005). Heterogeneous firms and trade: Testable and untestable properties of the melitz model. Working Paper 11471, National Bureau of Economic Research.

Baldwin, R. and J. Harrigan (2011). Zeros, quality, and space: Trade theory and trade evidence. American Economic Journal: Microeconomics 3(2), 60-88.

Berman, E., J. Bound, and Z. Griliches (1994). Changes in the demand for skilled labor within us manufacturing industries: Evidence from the annual survey of manufacturing. Quarterly Journal of Economics 109(2), 367-97.

Bernard, A., J. Eaton, J. Jensen, and S. Kortum (2003). Plants and productivity in international trade. American Economic Review 93(4), 1268.

Bernard, A. and J. Jensen (1997). Exporters, skill upgrading, and the wage gap. Journal of International Economics 42(1-2), 3-31.

Bernard, A. and J. Jensen (1999). Exceptional exporter performance: cause, effect, or both? Journal of international economics 47(1), 1-25.

Bernard, A., J. Jensen, S. Redding, and P. Schott (2007). Firms in international trade. The Journal of Economic Perspectives, 105-130.

Bernard, A., S. Redding, and P. Schott (2007). Comparative advantage and heterogeneous firms. Review of Economic Studies 74(1), 31-66.

Burstein, A. and J. Vogel (2010). Globalization, technology, and the skill premium: A quantitative analysis. Working Paper 16459, National Bureau of Economic Research.

Bustos, P. (2011). The impact of trade on technology and skill upgrading evidence from argentina. Working Papers, Universitat Pompeu Fabra. Departamento de Economía y Empresa (1189).

Cameron, A. and P. Trivedi (2005). Microeconometrics: methods and applications. Cambridge Univ Pr.

Davis, D. and J. Harrigan (2011). Good jobs, bad jobs, and trade liberalization. Journal of International Economics.

Dornbusch, R., S. Fischer, and P. Samuelson (1980). Heckscher-Ohlin trade theory with a continuum of goods. The Quarterly Journal of Economics 95(2), 203-224.

Dunne, T., L. Foster, J. Haltiwanger, and K. Troske (2004). Wage and productivity dispersion in united states manufacturing: The role of computer investment. Journal of Labor Economics 22(2), 397-429.

Feenstra, R. C. and G. S. Hanson (1985). Foreign investment, outsourcing, and relative wages. In R. C. Feenstra, G. M. Grossman, and D. A. Irwin (Eds.), The Political Economy of Trade Policy: Essays in honor of Jagdish Bhagwati, pp. 89-128. Cambridge: MIT Press.

Goldberg, P. and N. Pavcnik (2007). Distributional effects of globalization in developing countries. Journal of Economic Literature 45(1), 39-82.

Goldin, C. and L. F. Katz (2008). The Race Between Education and Technology. Cambridge: Belknap Harvard University Press. 
Helpman, E. and P. R. Krugman (1985). Market structure and foreign trade. MIT press Cambridge, MA.

Kugler, M. and E. Verhoogen (2010). Prices, Plant Size, and Product Quality. Review of Economic Studies, forthcoming.

Melitz, M. (2003). The impact of trade on intra-industry reallocations and aggregate industry productivity. Econometrica 71(6), 1695-1725.

Nelsen, R. (2006). An introduction to copulas. Springer Us.

Pavcnik, N. (2002). Trade liberalization, exit, and productivity improvements: Evidence from Chilean plants. Review of Economic Studies 69(1), 245-276.

Romalis, J. (2004). Factor proportions and the structure of commodity trade. American Economic Review $94(1), 67-97$.

Stern, S. (1997). Simulation-based estimation. Journal of Economic Literature 35(4), 2006-2039.

Trefler, D. (2004). The long and short of the canada-us free trade agreement. The American Economic Review 94(4), 870-895.

Vannoorenberghe, G. (2011). Trade between symmetric countries, heterogeneous firms, and the skill premium. Canadian Journal of Economics/Revue canadienne d'économique 44(1), 148-170.

Verhoogen, E. (2008). Trade, Quality Upgrading, and Wage Inequality in the Mexican Manufacturing Sector. Quarterly Journal of Economics 123(2), 489-530.

Xiang, C. (2005). New goods and the relative demand for skilled labor. Review of Economics and Statistics $87(2), 285-298$.

Yeaple, S. (2005). A simple model of firm heterogeneity, international trade, and wages. Journal of international Economics 65(1), 1-20.

Zhu, S. and D. Trefler (2005). Trade and inequality in developing countries: a general equilibrium analysis. Journal of International Economics 65(1), 21-48. 
Figure 1: Sorting and the technology space.

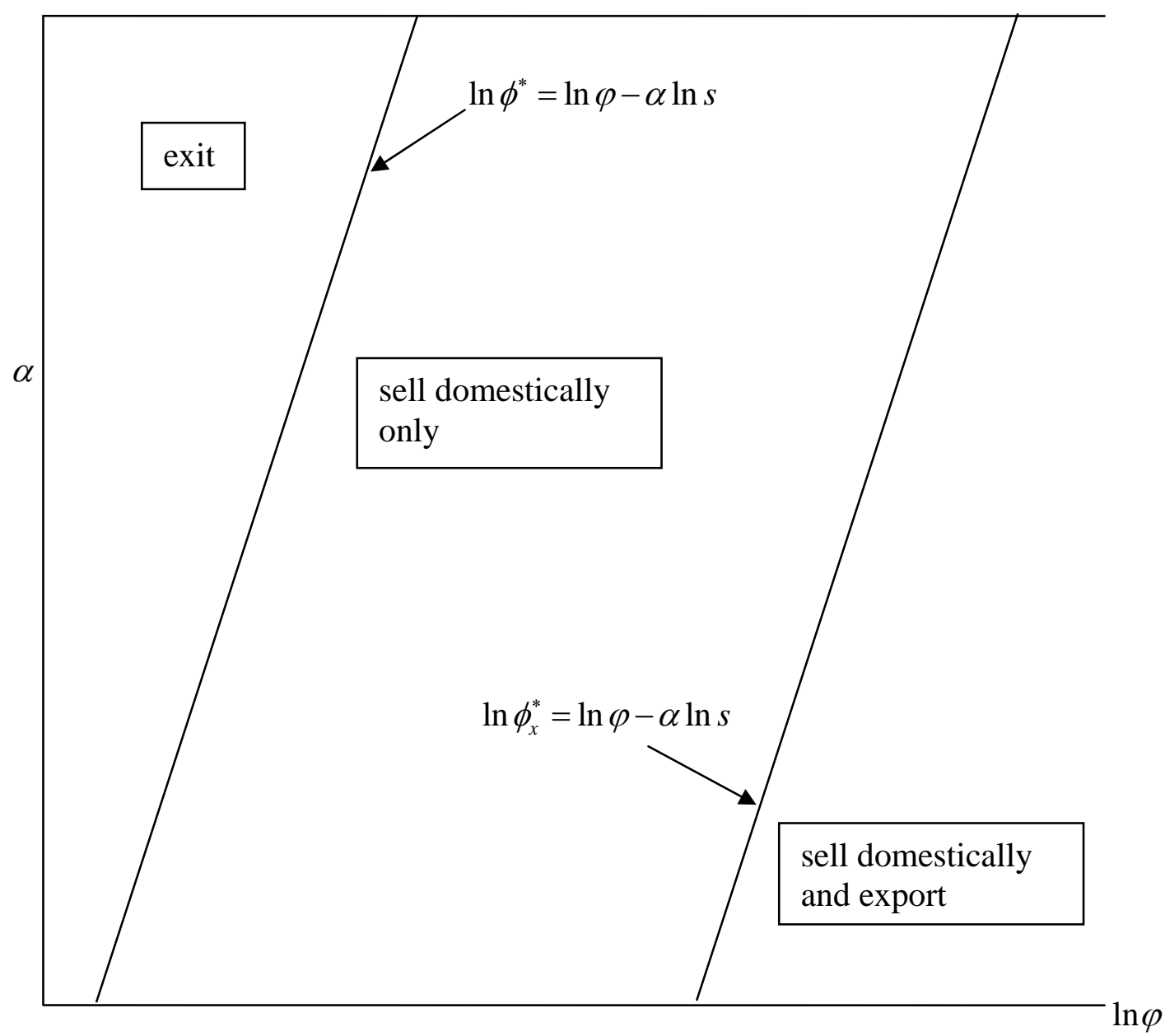

Notes to Figure 1 Log inverse unit cost is $\ln \phi=\ln \varphi-\alpha \ln s, s>1$ (for the purpose of these figures, we choose the unskilled wage $w$ as our numeraire). The survival cutoff $\phi^{*}$ and the export cutoff $\phi_{x}^{*}$ partition the space into three regions: technology draws where costs are too high to survive in equilibrium, cost draws low enough for profitable domestic sales but too high for exporting, and cost draws low enough for profitable exporting. 
Figure 2: Trade liberalization

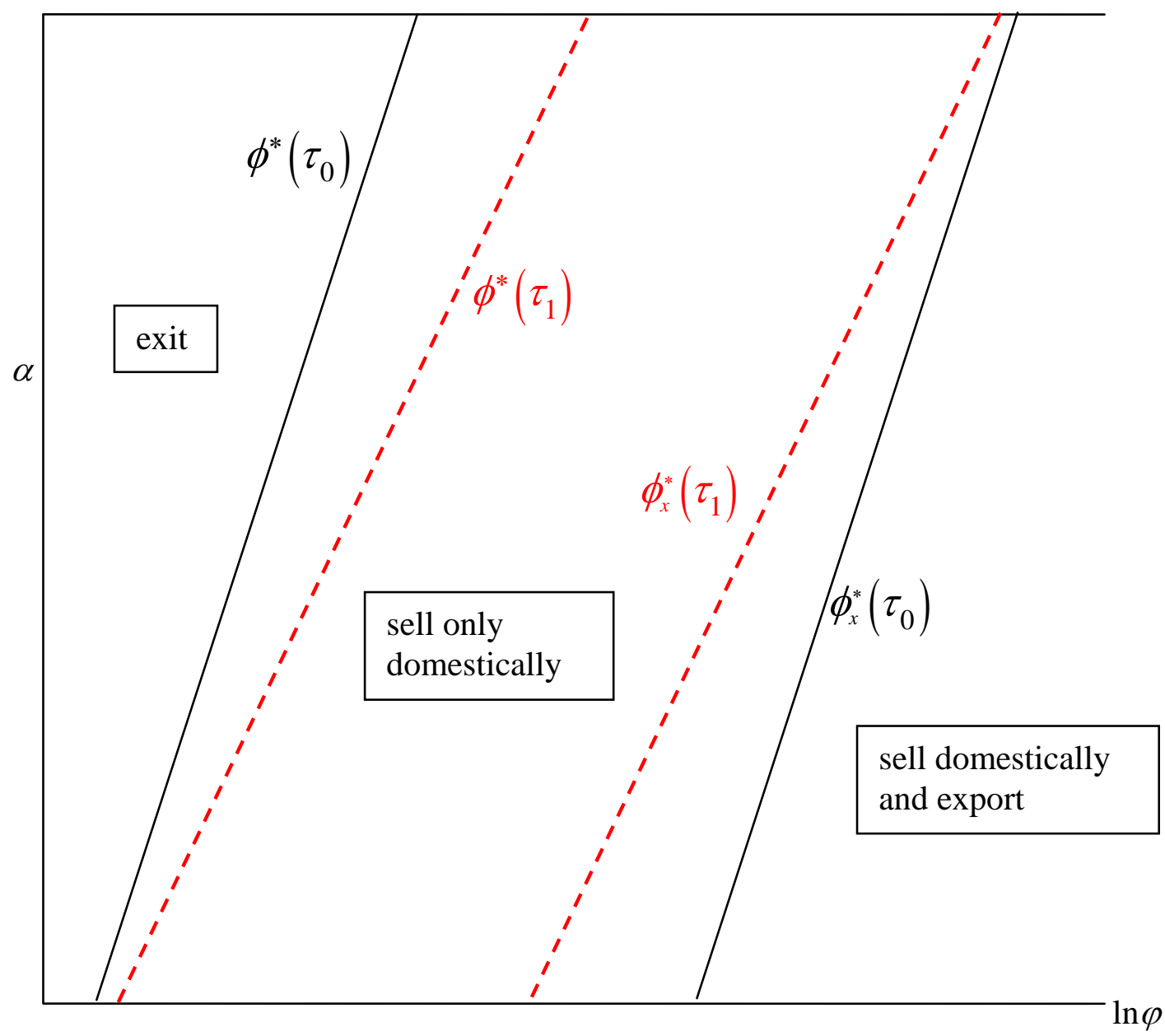

Notes to Figure 2 The red dotted lines show what happens when $\tau$ falls: survival cutoff rises, the export cutoff falls, and the slope $\frac{1}{\ln s}$ gets flatter as the skill premium rises. 
Figure 3: Specialization

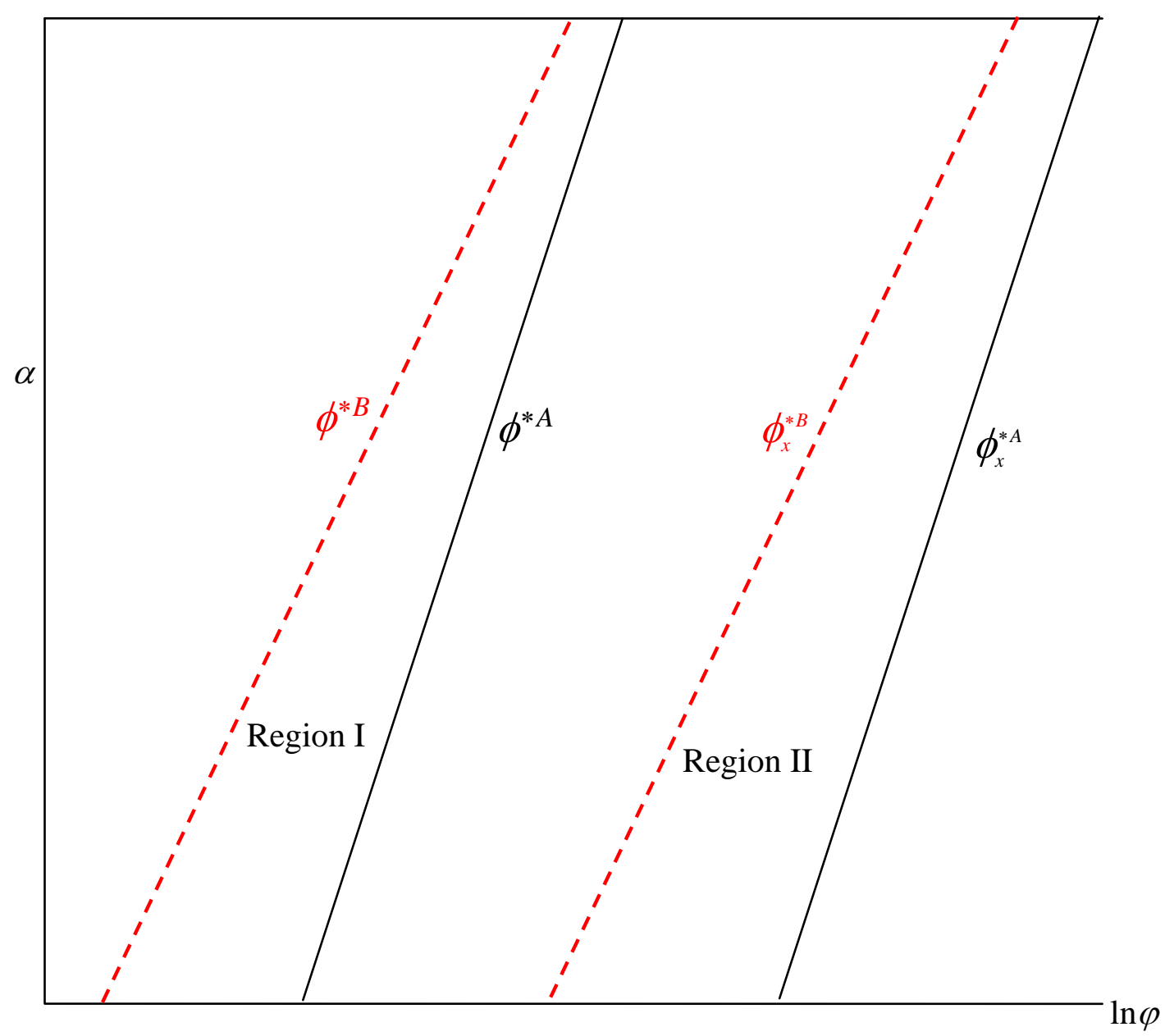

Notes to Figure 3 The black solid lines are the survival and export cutoffs for country $A$, and the red dotted lines are the survival and export cutoffs for country $B$. Region I contains non-exporters in $B$ who would not survive in $A$, and Region II contains exporters in $B$ who are non-exporters in $A$. 
Table 1 - Descriptive statistics for Chilean plants, 1995

\begin{tabular}{|ccccc|}
\hline & mean & median & std. dev. & skew \\
\hline log revenue & \multicolumn{5}{c}{ all } & 13.2 & 13.0 & 1.62 & 0.575 \\
domestic & 12.7 & 12.6 & 1.36 & 0.643 \\
exporters & 14.7 & 14.6 & 1.47 & 0.216 \\
\hline log wage & & & \\
all & 7.63 & 7.60 & 0.581 & 0.283 \\
domestic & 7.51 & 7.49 & 0.536 & 0.305 \\
exporters & 8.00 & 8.00 & 0.563 & 0.026 \\
\hline white-collar employment share \\
all & 0.233 & 0.200 & 0.151 & 1.20 \\
domestic & 0.222 & 0.189 & 0.145 & 1.28 \\
exporters & 0.268 & 0.236 & 0.164 & 0.96 \\
\hline white-collar wage bill share & & & \\
all & 0.356 & 0.330 & 0.197 & 0.577 \\
domestic & 0.326 & 0.300 & 0.185 & 0.696 \\
exporters & 0.448 & 0.434 & 0.205 & 0.182 \\
\hline
\end{tabular}

Notes to Table 1: Source: Annual National Industrial Survey of Chile, 1995. Sample size is 4,603 total manufacturing plants, of which 3,485 (76\%) are non-exporters and 1,118 (24\%) are exporters. Units for revenue and wages are 1000's of pesos.

Table 2 - Correlations across Chilean plants, 1995

\begin{tabular}{|c|c|c|c|}
\hline & $\begin{array}{c}\text { log } \\
\text { revenue }\end{array}$ & log wage & $\begin{array}{l}\text { skill emp } \\
\text { share }\end{array}$ \\
\hline \multicolumn{4}{|l|}{ all plants $(N=4603)$} \\
\hline log wage & 0.65 & 1.0 & \\
\hline skill emp share & 0.23 & 0.43 & 1.0 \\
\hline skill wage bill share & 0.39 & 0.54 & 0.82 \\
\hline \multicolumn{4}{|c|}{ non-exporting plants $(N=3485)$} \\
\hline log wage & 0.58 & 1.0 & \\
\hline skill emp share & 0.18 & 0.35 & 1.0 \\
\hline skill wage bill share & 0.32 & 0.47 & 0.82 \\
\hline \multicolumn{4}{|c|}{ exporting plants $(N=1118)$} \\
\hline log wage & 0.57 & 1.0 & \\
\hline skill emp share & 0.24 & 0.58 & 1.0 \\
\hline skill wage bill share & 0.27 & 0.56 & 0.83 \\
\hline
\end{tabular}

Notes to Table 2: Source: Annual National Industrial Survey of Chile, 1995. All correlations are statistically significant at $p$-value of 0.01 . 
Table 3 - Chilean plant characteristics and exporting, 1990-1995

\begin{tabular}{|c|c|c|c|c|c|c|}
\hline & (1) & (2) & (3) & (4) & (5) & (6) \\
\hline \multicolumn{7}{|c|}{ A. Dependent Variable: Log Revenue } \\
\hline \multirow[t]{2}{*}{4 years before export } & & $-0.261 * * *$ & & $-0.196 * * *$ & & - \\
\hline & & $(0.059)$ & & $(0.059)$ & & - \\
\hline \multirow[t]{2}{*}{3 years before export } & & $-0.151^{* * *}$ & & $-0.106 * *$ & & $-0.187 * * *$ \\
\hline & & $(0.042)$ & & $(0.042)$ & & $(0.060)$ \\
\hline \multirow[t]{2}{*}{2 years before export } & & $-0.137 * * *$ & & $-0.100 * * *$ & & $-0.096 * * *$ \\
\hline & & $(0.031)$ & & $(0.031)$ & & $(0.034)$ \\
\hline \multirow[t]{2}{*}{1 years before export } & & $-0.079 * * *$ & & $-0.055^{* *}$ & & $-0.064 * * *$ \\
\hline & & $(0.026)$ & & $(0.022)$ & & $(0.022)$ \\
\hline \multirow[t]{2}{*}{ Export dummy } & $0.168 * * *$ & $0.096 * * *$ & $0.130 * * *$ & $0.064^{* * *}$ & $0.214^{* * *}$ & $0.090 * * *$ \\
\hline & $(0.018)$ & $(0.020)$ & $(0.015)$ & $(0.016)$ & $(0.022)$ & $(0.022)$ \\
\hline \multirow[t]{2}{*}{ Export year 2} & & $0.061 * * *$ & & $0.040 * * *$ & & $0.046 * * *$ \\
\hline & & $(0.014)$ & & $(0.012)$ & & $(0.013)$ \\
\hline \multirow[t]{2}{*}{ Export year 3} & & $0.085^{* * *}$ & & $0.049 * * *$ & & $0.049 * * *$ \\
\hline & & $(0.017)$ & & $(0.016)$ & & $(0.018)$ \\
\hline \multirow[t]{2}{*}{ Export year 4} & & $0.096 * * *$ & & $0.044 * *$ & & $0.048 * *$ \\
\hline & & $(0.020)$ & & $(0.019)$ & & $(0.021)$ \\
\hline \multirow[t]{2}{*}{ Export year 5} & & $0.133 * * *$ & & $0.101 * * *$ & & $0.099 * * *$ \\
\hline & & $(0.021)$ & & $(0.021)$ & & $(0.023)$ \\
\hline \multirow[t]{2}{*}{ Export year 6} & & $0.158 * * *$ & & $0.149 * * *$ & & $0.152 * * *$ \\
\hline & & $(0.026)$ & & $(0.027)$ & & $(0.028)$ \\
\hline Year effects & No & Yes & No & Yes & No & Yes \\
\hline$R^{2}$, within & 0.009 & 0.020 & 0.008 & 0.037 & 0.010 & 0.038 \\
\hline Observations & 26,817 & 26,817 & 17,820 & 17,820 & 15,468 & 15,468 \\
\hline Number of plants & 6,077 & 6,077 & 2,970 & 2,970 & 2,578 & 2,578 \\
\hline Number of exporters & 1,698 & 1,698 & 1,056 & 1,056 & 664 & 664 \\
\hline
\end{tabular}

Notes to Table 3: All regressions include plant fixed effects. Standard errors with clustering at the plant level are reported in parentheses. ${ }^{* *} p<0.01,{ }^{* *} p<0.05$, * $p<0.1$. In columns 1 and 2 we include all available plants. In columns 3 and 4 we restrict the sample to plants that survive the entire sample. In columns 5 and 6 we further restrict the sample by keeping only exporters that export continuously for at least two years and never stop exporting once they start (i.e. the last year of exporting is invariably 1995). Source: Annual National Industrial Survey of Chile 1990-1995. See text for more details. 
Table 3, continued - Chilean plant characteristics and exporting, 1990-1995

\begin{tabular}{|c|c|c|c|c|c|c|}
\hline & (1) & (2) & (3) & (4) & (5) & (6) \\
\hline \multicolumn{7}{|c|}{ B. Dependent Variable: Wage Bill Share of Skilled Workers } \\
\hline \multirow[t]{2}{*}{4 years before export } & & 0.0130 & & 0.0155 & & - \\
\hline & & (0.018) & & (0.018) & & - \\
\hline \multirow[t]{2}{*}{3 years before export } & & -0.0050 & & -0.0038 & & 0.0010 \\
\hline & & $(0.012)$ & & $(0.012)$ & & (0.018) \\
\hline \multirow[t]{2}{*}{2 years before export } & & 0.0040 & & 0.0075 & & -0.0035 \\
\hline & & (0.009) & & (0.009) & & $(0.012)$ \\
\hline \multirow[t]{2}{*}{1 years before export } & & 0.0032 & & 0.0060 & & 0.0012 \\
\hline & & (0.006) & & $(0.007)$ & & (0.010) \\
\hline \multirow[t]{2}{*}{ Export dummy } & 0.0005 & 0.0013 & 0.0019 & 0.0029 & 0.0067 & 0.0057 \\
\hline & $(0.004)$ & $(0.004)$ & (0.004) & $(0.005)$ & (0.008) & $(0.008)$ \\
\hline \multirow[t]{2}{*}{ Export year 2} & & -0.0008 & & 0.0001 & & -0.0004 \\
\hline & & $(0.004)$ & & $(0.004)$ & & $(0.005)$ \\
\hline \multirow[t]{2}{*}{ Export year 3} & & -0.0008 & & 0.0012 & & -0.0011 \\
\hline & & $(0.004)$ & & $(0.005)$ & & $(0.005)$ \\
\hline \multirow[t]{2}{*}{ Export year 4} & & 0.0031 & & 0.0000 & & -0.0001 \\
\hline & & $(0.005)$ & & $(0.005)$ & & $(0.006)$ \\
\hline \multirow[t]{2}{*}{ Export year 5} & & -0.0001 & & -0.0050 & & -0.0056 \\
\hline & & $(0.006)$ & & $(0.006)$ & & $(0.007)$ \\
\hline \multirow[t]{2}{*}{ Export year 6} & & -0.0023 & & -0.0038 & & -0.0056 \\
\hline & & $(0.007)$ & & $(0.007)$ & & (0.008) \\
\hline Year effects & No & Yes & No & Yes & No & Yes \\
\hline$R^{2}$, within & 0.000 & 0.000 & 0.000 & 0.001 & 0.000 & 0.001 \\
\hline Observations & 26,817 & 26,817 & 17,820 & 17,820 & 15,468 & 15,468 \\
\hline Number of plants & 6,077 & 6,077 & 2,970 & 2,970 & 2,578 & 2,578 \\
\hline Number of exporters & 1,698 & 1,698 & 1,056 & 1,056 & 664 & 664 \\
\hline
\end{tabular}

Notes to Table 3: All regressions include plant fixed effects. Standard errors with clustering at the plant level are reported in parentheses. ${ }^{* *} p<0.01,{ }^{* *} p<0.05$, * $p<0.1$. In columns 1 and 2 we include all available plants. In columns 3 and 4 we restrict the sample to plants that survive the entire sample. In columns 5 and 6 we further restrict the sample by keeping only exporters that export continuously for at least two years and never stop exporting once they start (i.e. the last year of exporting is invariably 1995). Source: Annual National Industrial Survey of Chile 1990-1995. See text for more details. 
Table 4 Quantitative effects of opening to trade panel A: skill biased technology, $\theta=11$

\begin{tabular}{|c|c|cc|ccc|}
\hline \multicolumn{2}{|c|}{$\tau$} & \multicolumn{2}{c|}{ symmetric } & \multicolumn{3}{c|}{ asymmetric } \\
Real & $\infty$ & 100 & 100 & 100 & 100 & 1 \\
GDP & 1.4 & 106 & 107 & 106 & 106 & 1 \\
& 1.0 & 119 & 120 & 119 & 117 & 0.98 \\
\hline \multirow{2}{*}{ Skill } & $\infty$ & 2.84 & 1.99 & 1.99 & 4.58 & 2.30 \\
premium & 1.4 & 2.98 & 2.04 & 2.03 & 4.84 & 2.39 \\
& 1.0 & 3.06 & 2.06 & 2.06 & 4.97 & 2.41 \\
\hline Real & $\infty$ & 284 & 199 & 199 & 357 & 1.79 \\
skilled & 1.4 & 312 & 216 & 213 & 390 & 1.83 \\
wage & 1.0 & 352 & 243 & 242 & 441 & 1.82 \\
\hline Real & $\infty$ & 100 & 100 & 100 & 78 & 0.78 \\
unskilled & 1.4 & 104 & 106 & 105 & 81 & 0.78 \\
wage & 1.0 & 115 & 118 & 117 & 89 & 0.75 \\
\hline
\end{tabular}

panel B: no skill bias in technology, $\theta=1$

\begin{tabular}{|c|c|cc|ccc|}
\hline \multicolumn{2}{|c|}{} & \multicolumn{2}{c|}{ symmetric } & \multicolumn{3}{c|}{ asymmetric } \\
& $\tau$ & $(H / L)=0.26$ & $(H / L)=0.5$ & $(H / L)^{A}=0.5$ & $(H / L)^{B}=0.1$ & $B / A$ \\
\hline \multirow{2}{*}{ Real } & $\infty$ & 100 & 100 & 100 & 100 & 1 \\
GDP & 1.4 & 107 & 107 & 107 & 107 & 1 \\
& 1.0 & 121 & 121 & 121 & 121 & 1 \\
\hline \multirow{2}{*}{ Skill } & $\infty$ & 1.64 & 1.06 & 1.06 & 3.12 & 2.94 \\
premium & 1.4 & 1.62 & 1.06 & 1.06 & 3.11 & 2.94 \\
& 1.0 & 1.62 & 1.06 & 1.06 & 3.11 & 2.94 \\
\hline Real & $\infty$ & 163 & 106 & 106 & 238 & 2.24 \\
skilled & 1.4 & 175 & 114 & 114 & 255 & 2.24 \\
wage & 1.0 & 196 & 128 & 128 & 287 & 2.25 \\
\hline Real & $\infty$ & 100 & 100 & 100 & 76.4 & 0.76 \\
unskilled & 1.4 & 108 & 108 & 107 & 82.0 & 0.76 \\
wage & 1.0 & 121 & 121 & 121 & 92.4 & 0.76 \\
\hline
\end{tabular}

Notes to Table 4: real GDP and real wages are normalized by real GDP of country A in autarky $(=100)$ and by real wage of unskilled labor in country $A$ in autarky (=100), respectively. Skill premium not normalized. In asymmetric case, country B's labor force is adjusted to so that A and B have the same autarky real GDP. In symmetric case normalization is by corresponding values of same (symmetric) country in autarky. 
Table 5 Quantitative effects of skill accumulation in country B

\begin{tabular}{|lcccc|}
\hline & $(H / L)^{B}$ & country $A$ & country $B$ & $B / A$ \\
\hline Real & 0.5 & 100 & 100 & 1 \\
GDP & 0.3 & 99.6 & 90.7 & 0.91 \\
& 0.1 & 98.4 & 70.9 & 0.72 \\
\hline Skill & 0.5 & 2.04 & 2.04 & 1 \\
premium & 0.3 & 2.04 & 2.76 & 1.36 \\
& 0.1 & 2.03 & 4.84 & 2.39 \\
\hline Real & 0.5 & 204 & 204 & 1 \\
skilled & 0.3 & 203 & 240 & 1.18 \\
wage & 0.1 & 200 & 343 & 1.71 \\
\hline Real & 0.5 & 100 & 100 & 1 \\
unskilled & 0.3 & 99.6 & 86.8 & 0.87 \\
wage & 0.1 & 98.6 & 70.8 & 0.72 \\
\hline
\end{tabular}

Notes to Table 5: real GDP and real wages are normalized by real GDP and by real wage of unskilled labor at symmetry $(=100)$, respectively. Skill premium not normalized. Skill-biased technology and moderate trade costs, $\theta=11$ and $\tau=1.4$. 


\section{Figure 4}

\section{Distribution of white collar wage bill shares}

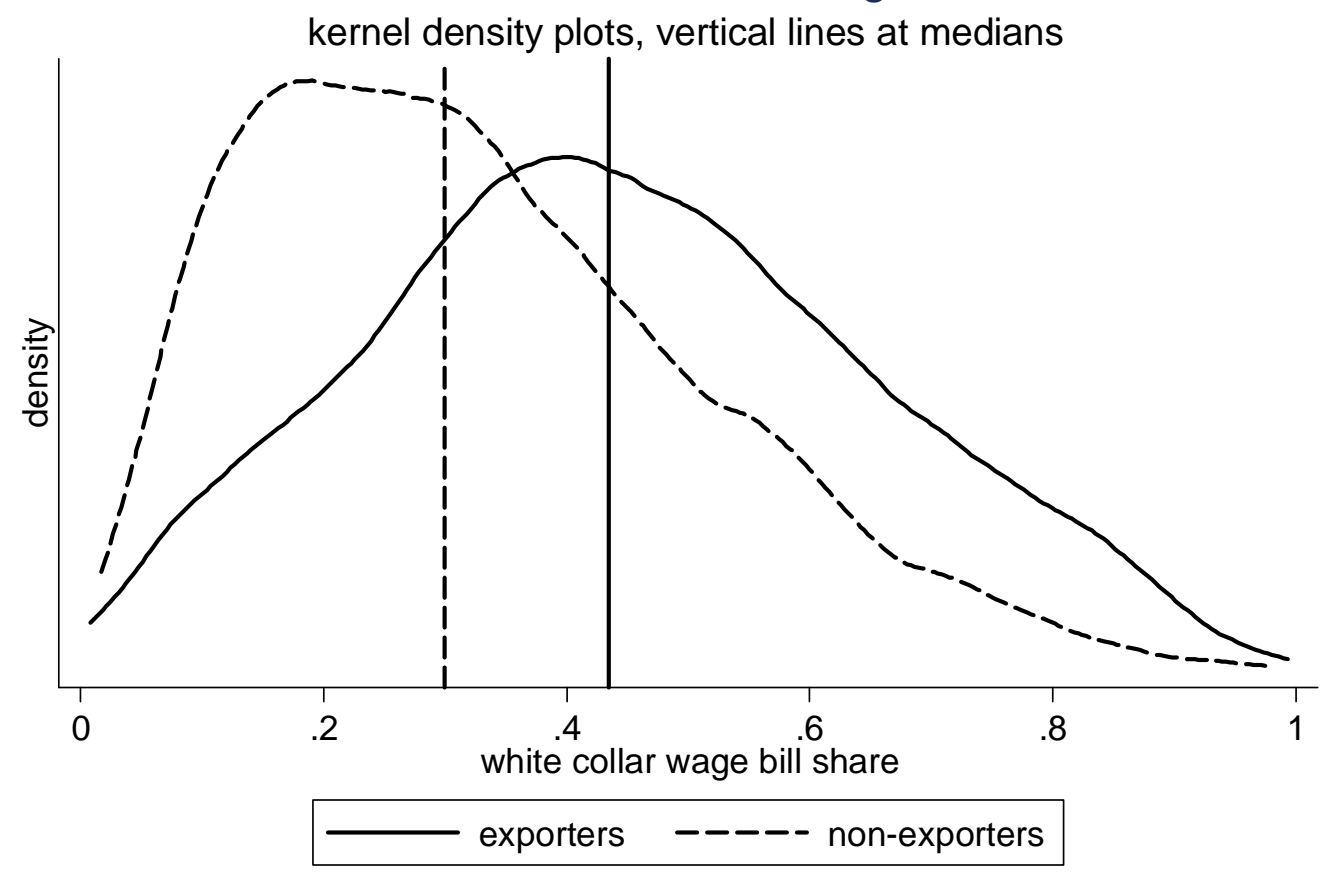

Notes to Figure 4: Data are white-collar employment shares in Chilean manufacturing plants in 1995, Annual National Industrial Survey of Chile. The sample includes 4603 plants, of which $24 \%$ export. 
Figure 5 - Skill share and log revenue, Chilean plants 1995

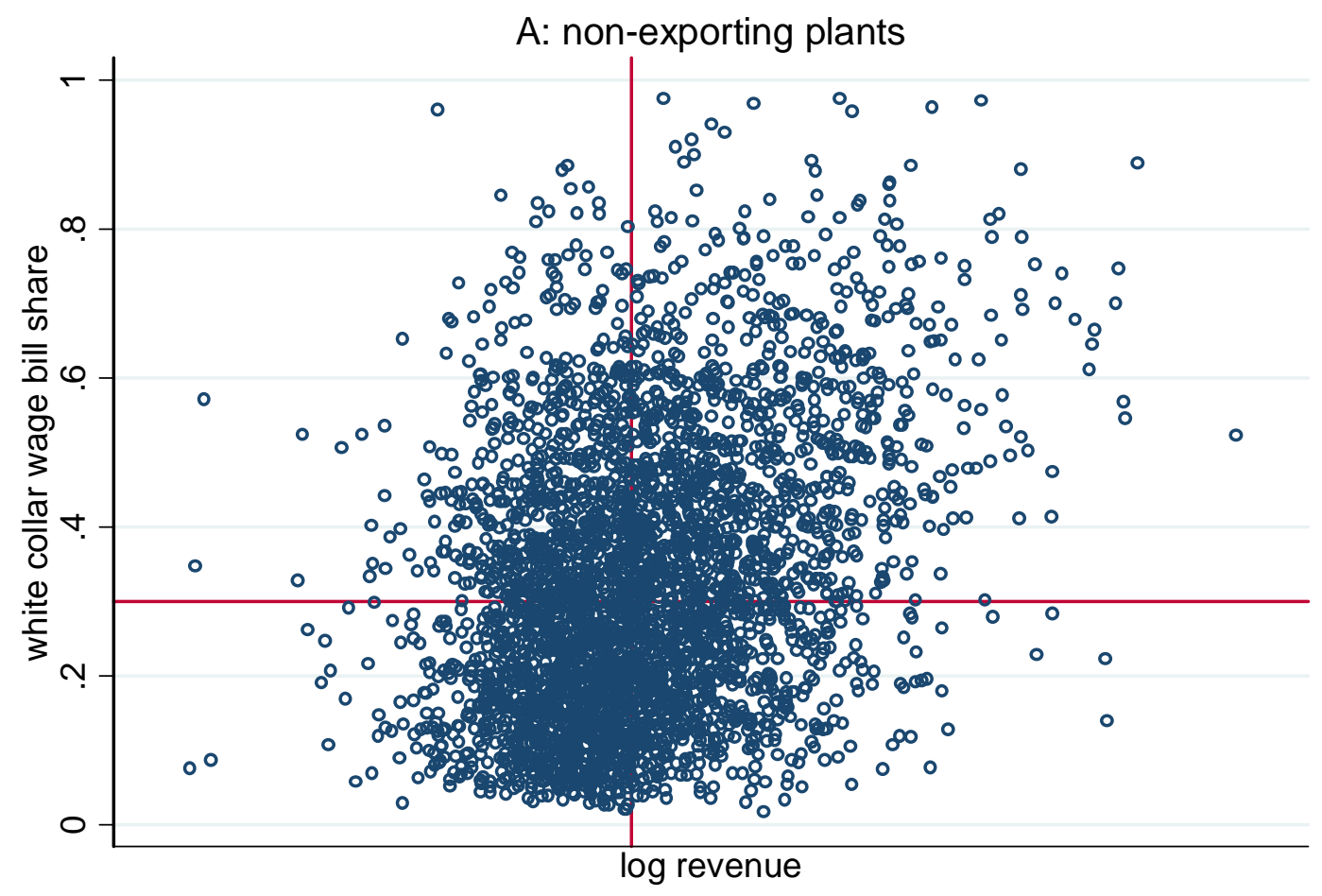

median values indicated by straight lines

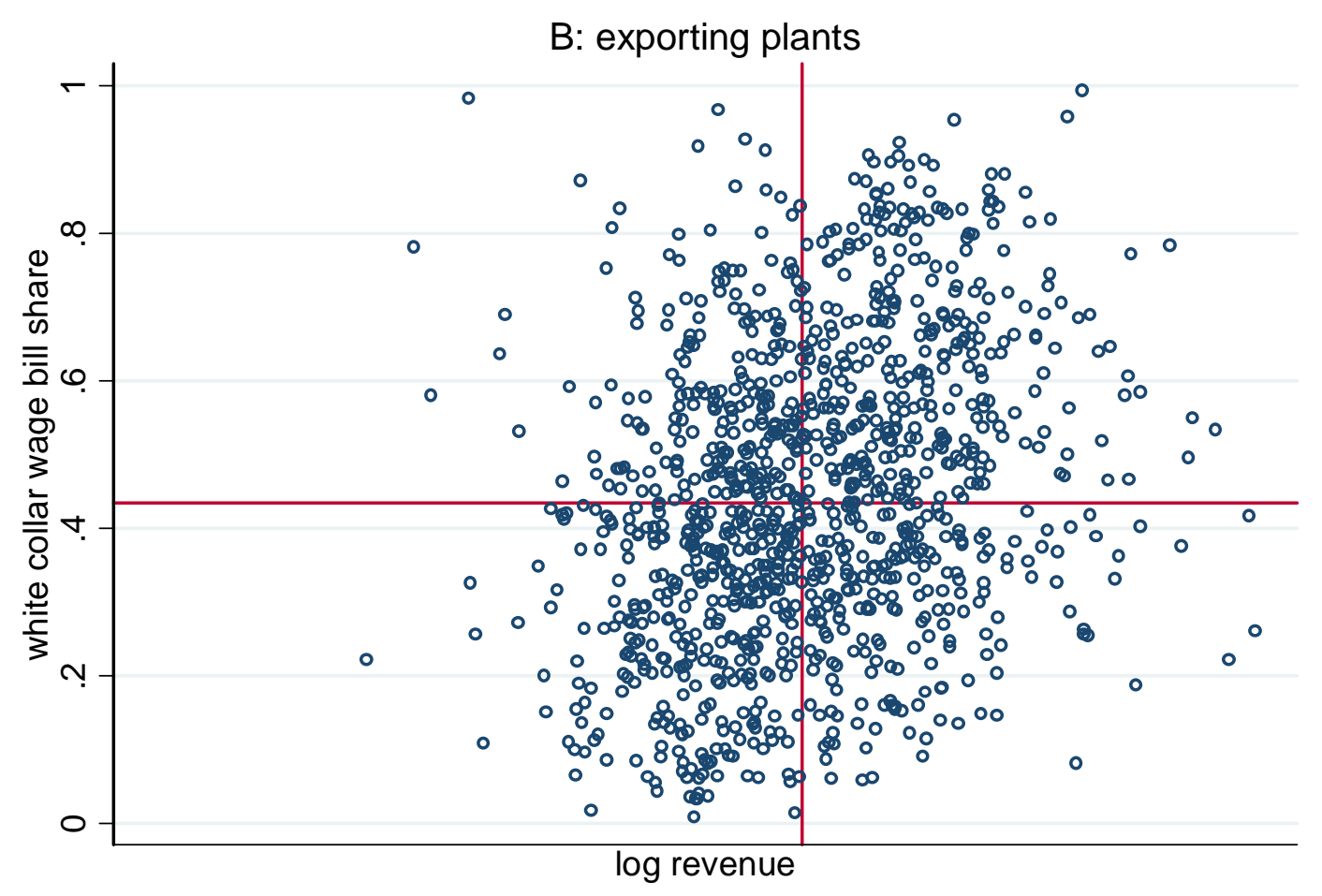

median values indicated by straight lines

Notes to Figure 5: see notes to Table 1. 
Figure 6a Trade liberalization between identical countries: gains from trade and entry

A. Aggregate Output

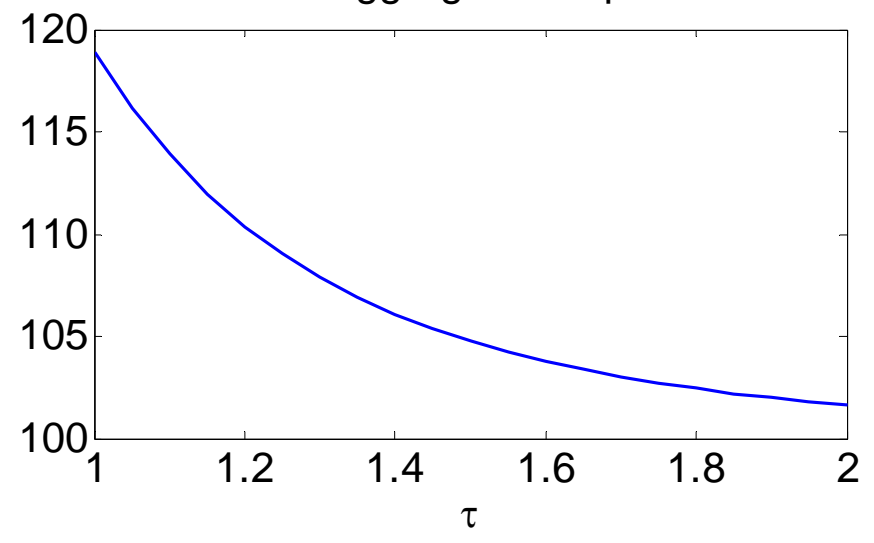

C. Firm Mass

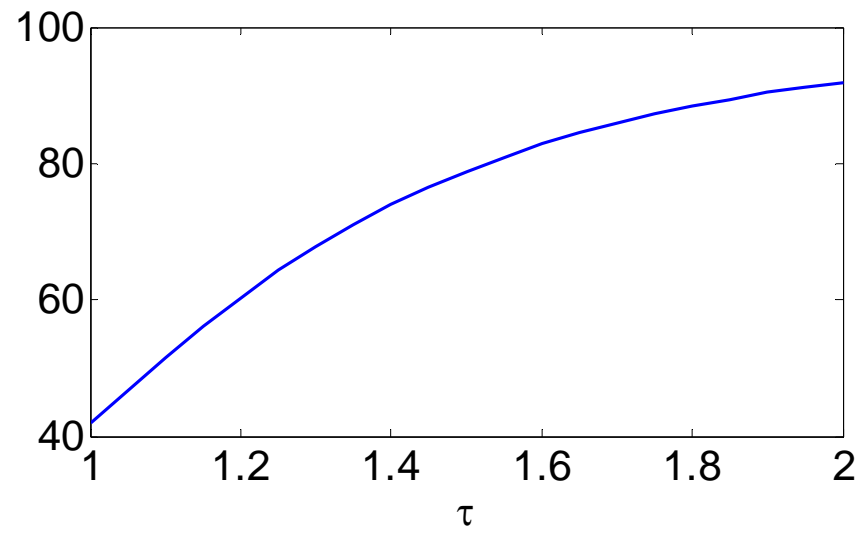

B. Cutoffs

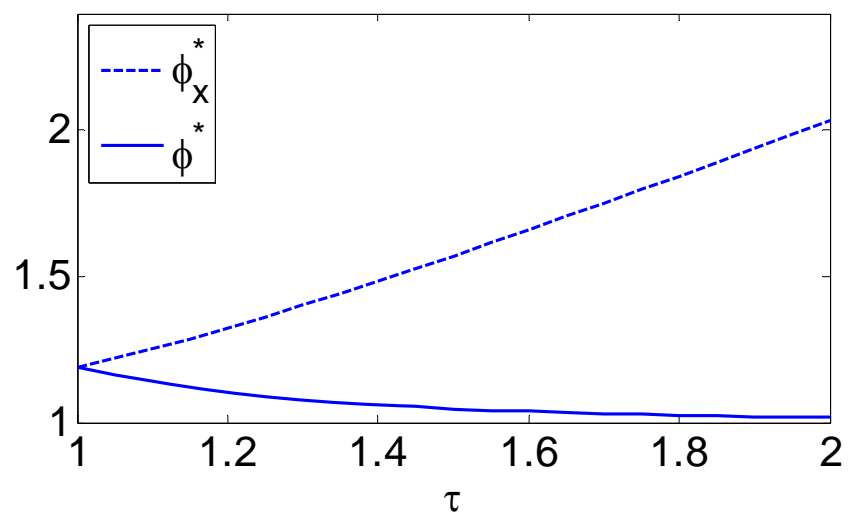

D. Probability of Entry

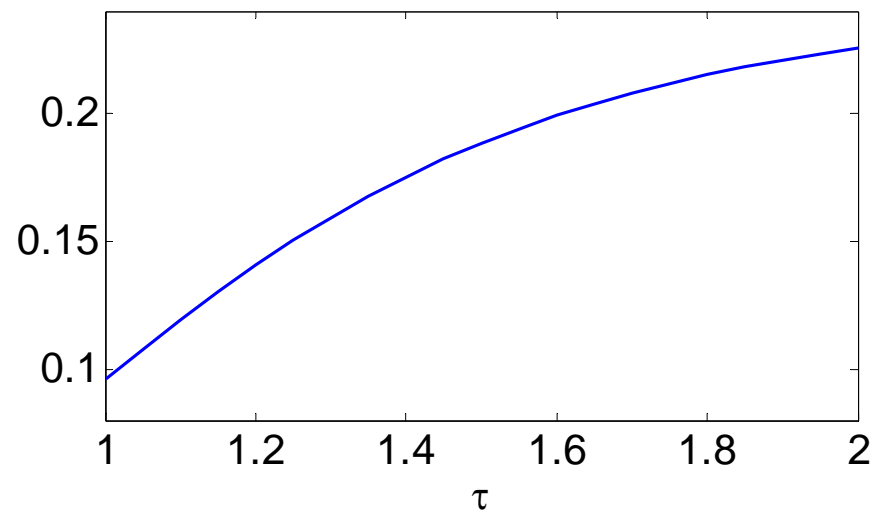

Notes to Figure 6a: Real GDP and firm mass normalized to 100 , and survival cutoff $\phi^{\star}$ normalized to one, in autarky. 
Figure 6b Trade liberalization between identical countries: prices

A. Relative Wage of Skilled Workers

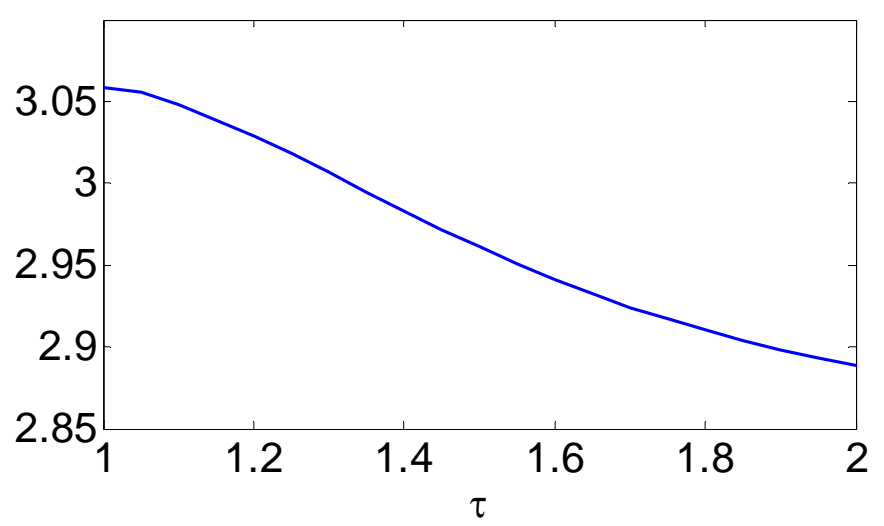

C. Real Wages

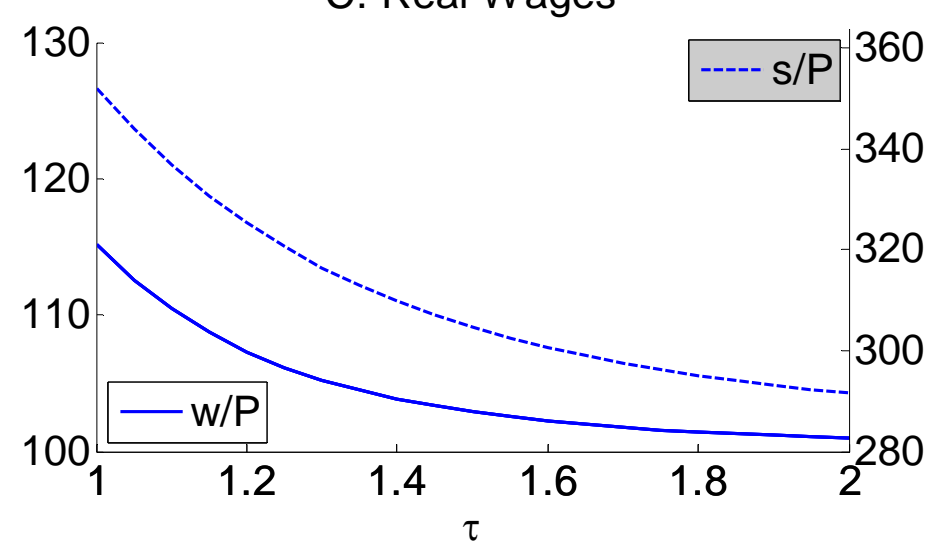

B. Price Index

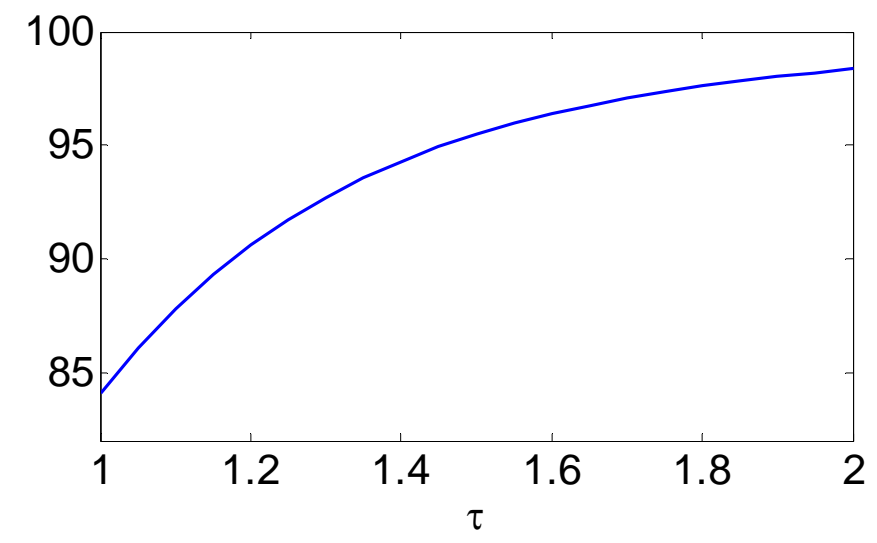

Notes to Figure 6b: Price index normalized to 100 , and real unskilled wage normalized to 100 , in autarky. 
Figure 7a Trade liberalization between asymmetric countries: gains from trade and entry
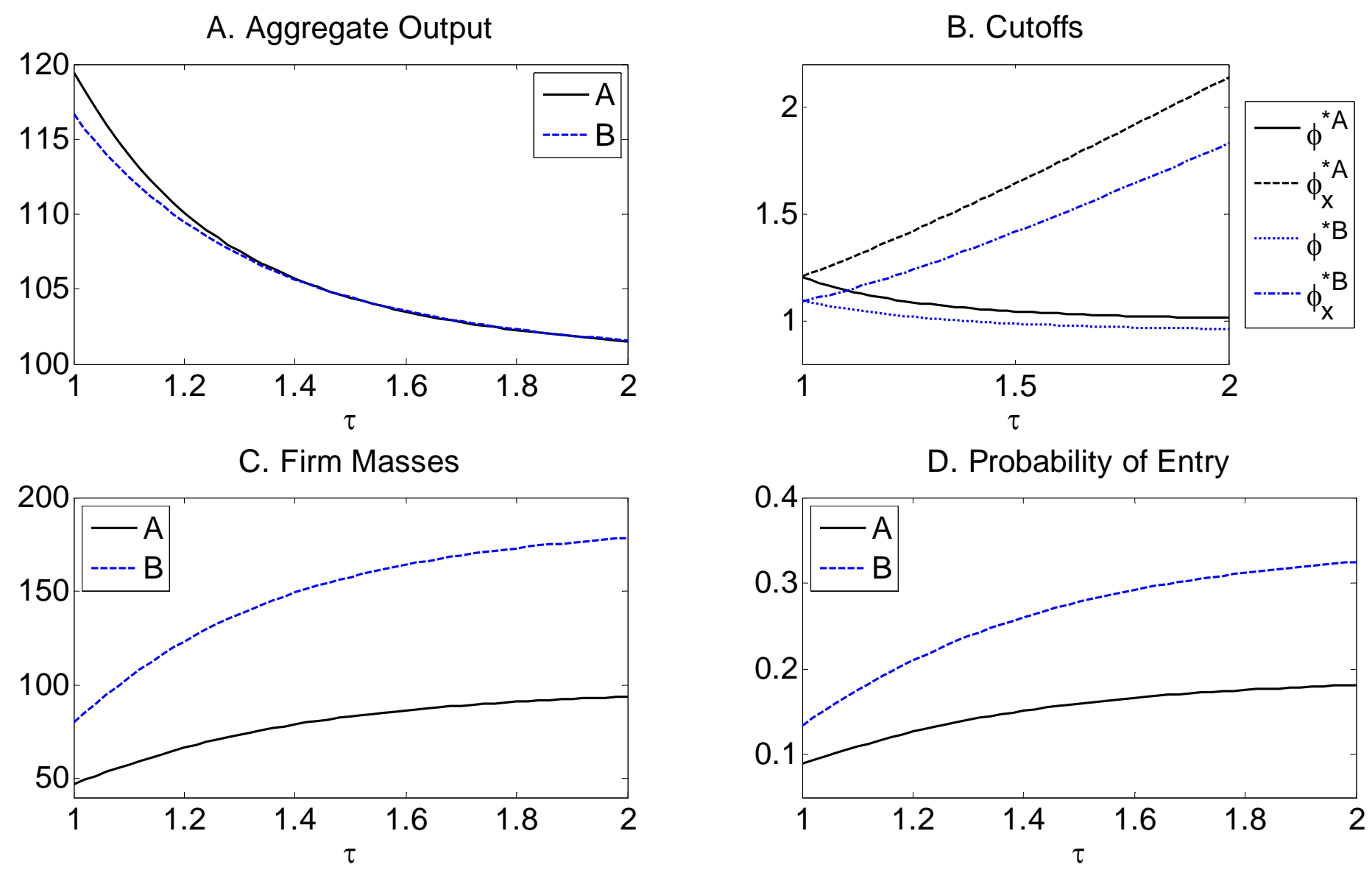

Notes to Figure 7a: Real GDP and firm mass normalized to 100 , and survival cutoff $\phi^{\star}$ normalized to one, in autarky in country A. Real GDP's equal in autarky by choice of population size. 
Figure 7b Trade liberalization between asymmetric countries: prices
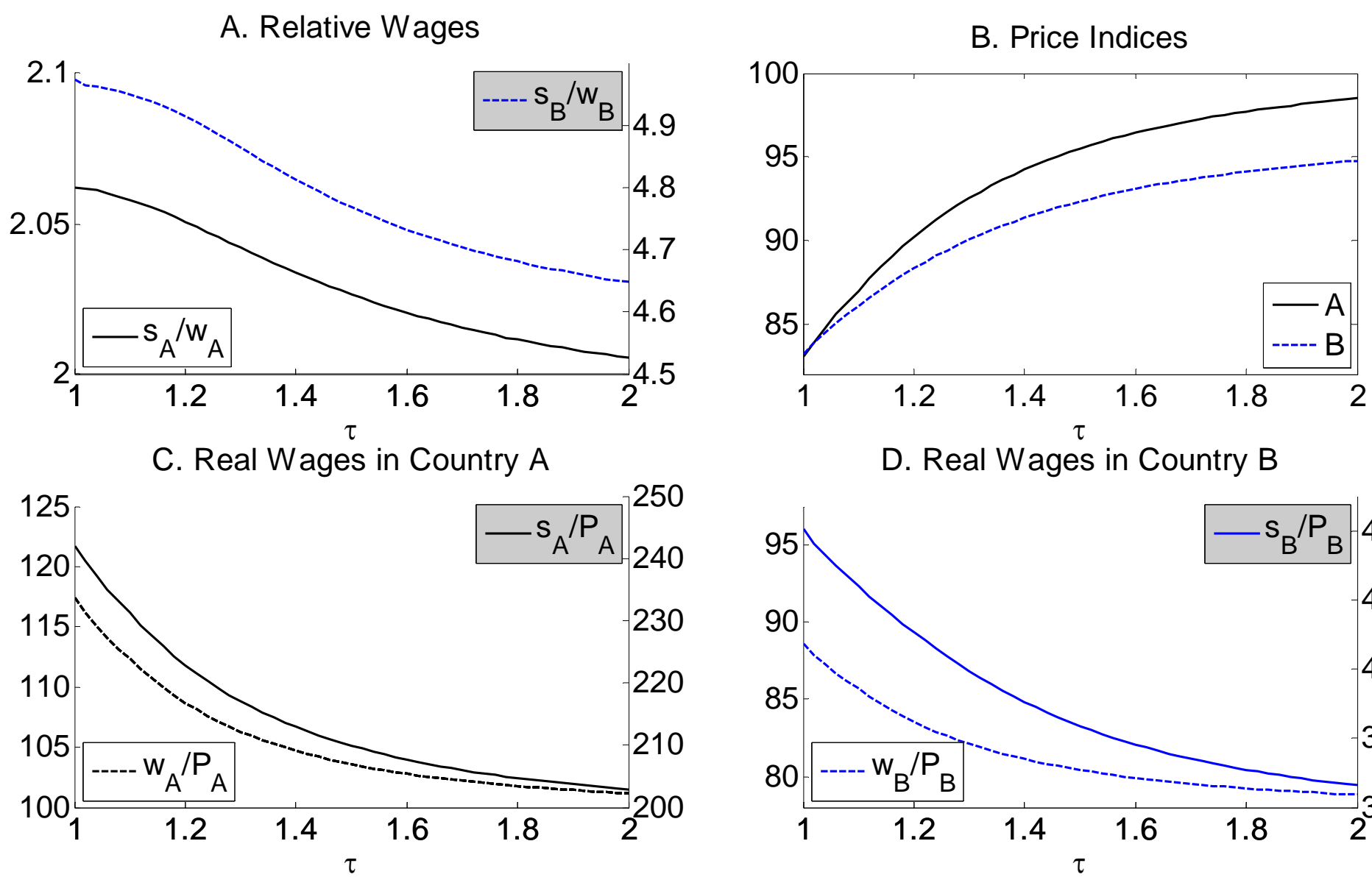

D. Real Wages in Country $B$

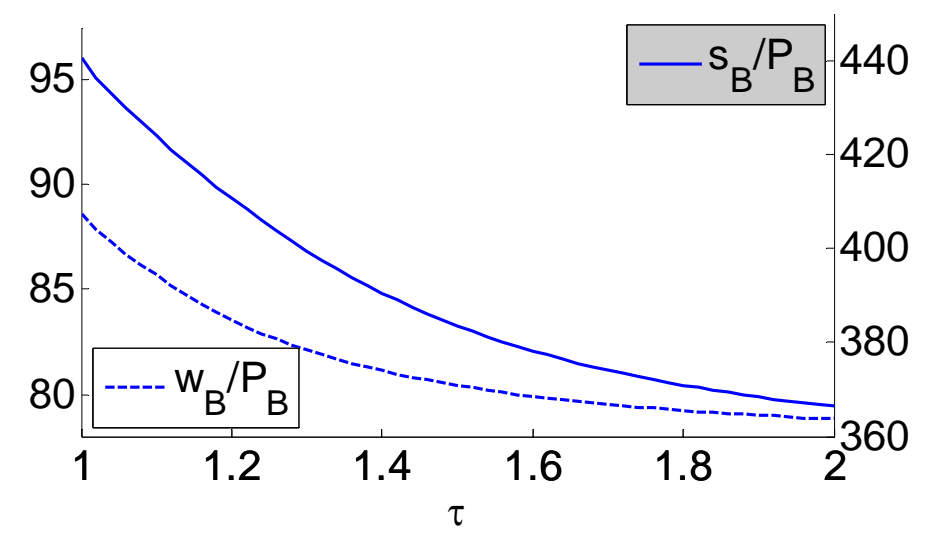

Notes to Figure $7 \mathrm{~b}$ : Price index in A and real unskilled wage in A both normalized to 100 in autarky. 
Figure 8 Log inverse unit cost distributions

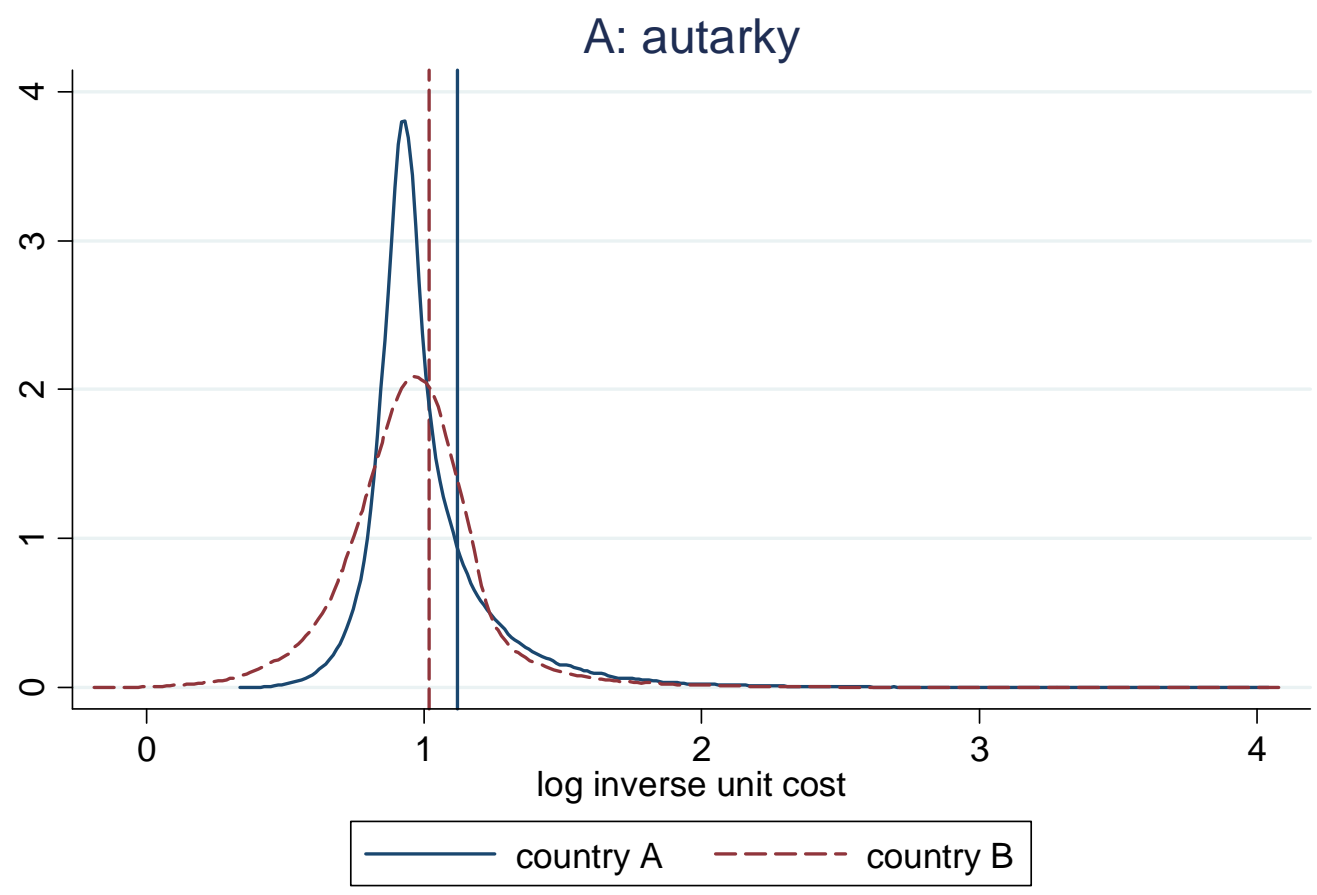

vertical lines are survival cutoffs

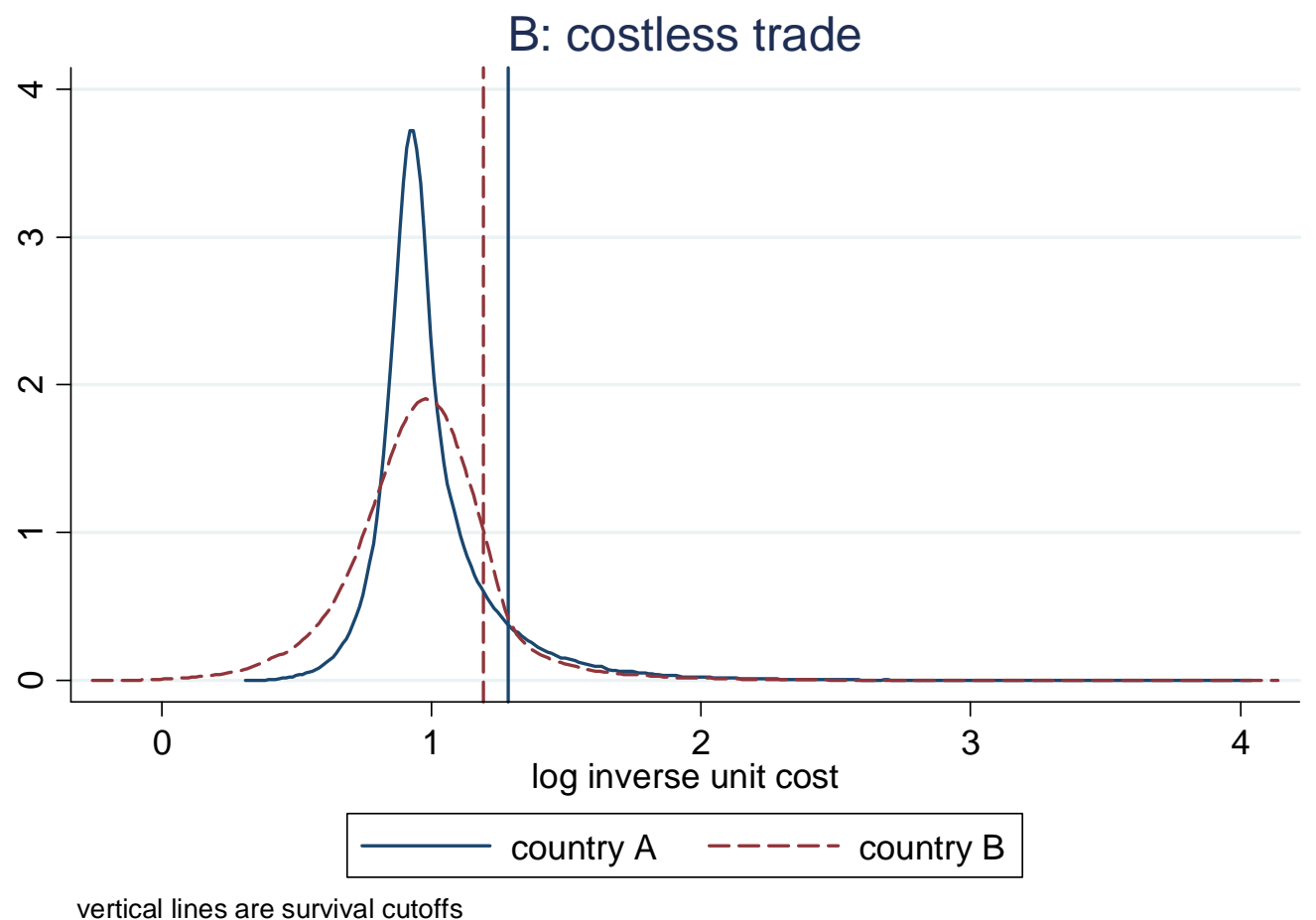

Notes to Figure 8: Kernel densities of ex ante log inverse unit cost $(\ln \phi)$ distributions, with ex post equilibrium survival cutoffs indicated by vertical lines. 
Figure 9 The factor content of trade
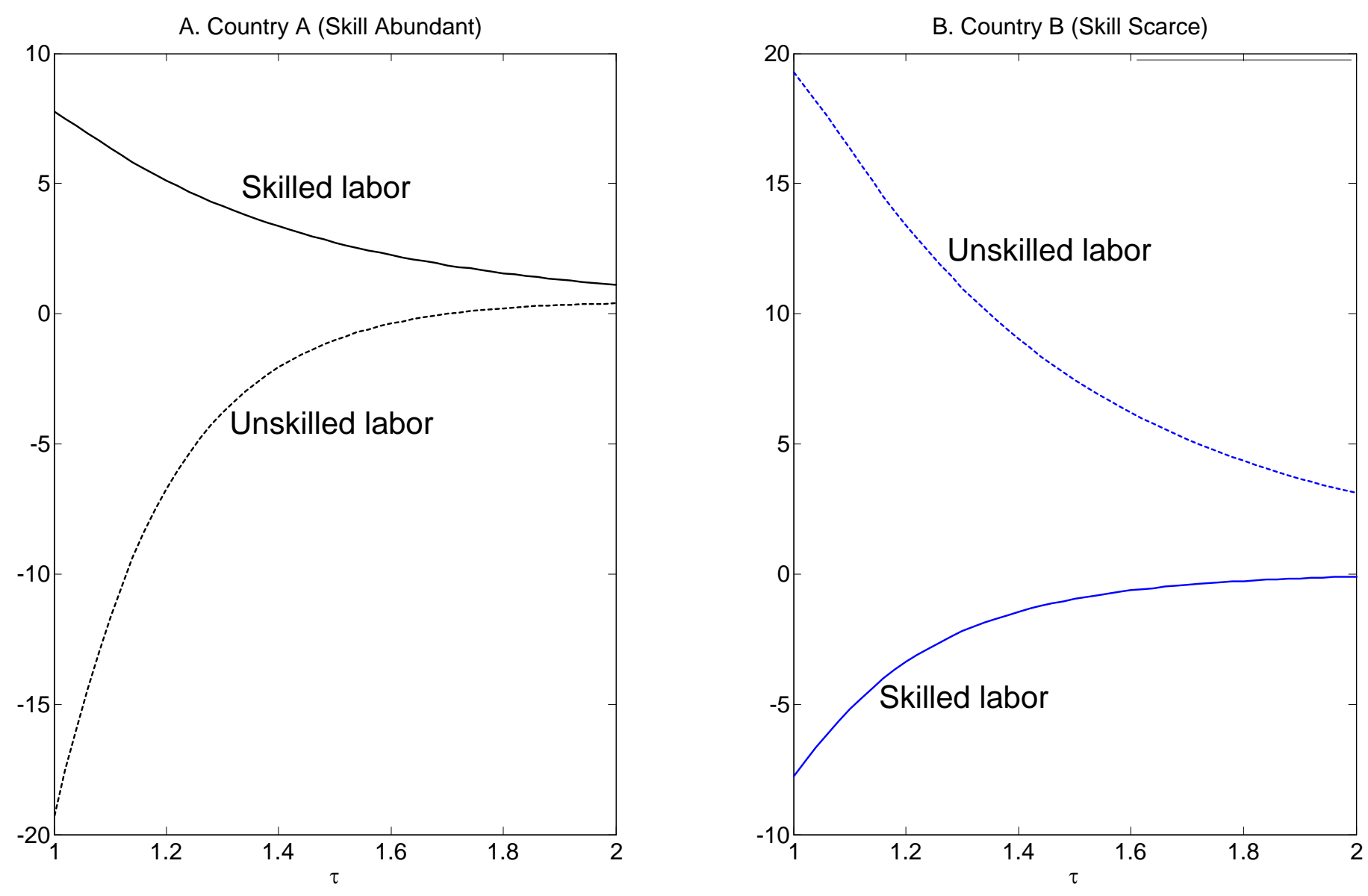

Notes to Figure 9 Units on vertical axis are net factor content of trade as a share of aggregate labor force. 


\section{APPENDIX 1}

This appendix proves Propositions 1 and 2 in the text. First we show that equilibrium is unique, and then we show that the movement from autarky to costly trade leads to an increase in the skill premium (in the skill-biased case) or no change in the skill premium (in the no-bias case). Throughout this appendix, we take the unskilled wage as our numeraire, so the skill premium $s$ is the relative wage of skilled versus unskilled workers.

Finding equilibrium requires simultaneously solving the labor market equilibrium and free entry conditions for the equilibrium values of $s$ and $\phi^{*}$ :

$$
\begin{gathered}
\int_{1}\left(s, \phi^{*}\right)=\frac{(\alpha, \varphi) \in D}{\iint_{(\alpha, \varphi) \in D} \tilde{H}_{d v} g(\alpha, \varphi) d \alpha d \varphi+\tau^{1-\sigma} \iint_{(\alpha, \varphi) \in X} \tilde{H}_{d v} g(\alpha, \varphi) d \alpha d \varphi+\tau^{1-\sigma} \iint_{(\alpha, \varphi) \in X} \tilde{L}_{d v} g(\alpha, \varphi) d \alpha d \varphi}=\frac{H}{L}, \\
\Theta_{2}\left(s, \phi^{*}\right)=f \iint_{(\alpha, \varphi) \in D}\left[\left(\frac{\phi(\alpha, \varphi)}{\phi^{*}}\right)^{\sigma-1}-1\right] g(\alpha, \varphi) d \alpha d \varphi+ \\
f_{x} \iint_{(\alpha, \varphi) \in X}\left[\left(\frac{\phi(\alpha, \varphi)}{\phi_{x}^{*}}\right)^{\sigma-1}-1\right] g(\alpha, \varphi) d \alpha d \varphi=\delta f_{e} .
\end{gathered}
$$

The cutoffs $\phi^{*}$ and $\phi_{x}^{*}$ define regions in $(\alpha, \varphi)$ space,

$$
\begin{aligned}
& D\left(\phi^{*}, s\right)=\left\{(\alpha, \varphi) \in[0,1] \times \mathbb{R}_{+}^{1}: \phi^{*} \leq \frac{\varphi}{s^{\alpha}}\right\}, \\
& X\left(\phi_{x}^{*}, s\right)=\left\{(\alpha, \varphi) \in[0,1] \times \mathbb{R}_{+}^{1}: \phi_{x}^{*} \leq \frac{\varphi}{s^{\alpha}}\right\} .
\end{aligned}
$$

All firms with $(\alpha, \varphi) \in D$ are active in equilibrium while firms with $(\alpha, \varphi) \in X$ are also exporters, where $X \subset D$. These regions are illustrated in Figure 1 .

\subsection{Uniqueness}

Our approach to uniqueness is to show that (63) and (64) define two curves in $\left(s, \phi^{*}\right)$ space, which we'll call the LME and FE schedules. Since these curves have opposite slopes, their intersection defines a unique solution. We show

$$
\begin{gathered}
L M E: \frac{d s}{d \phi^{*}}=-\frac{\partial \Theta_{1}\left(s, \phi^{*}\right)}{\partial \phi^{*}} / \frac{\partial \Theta_{1}\left(s, \phi^{*}\right)}{\partial s}>0 \\
F E: \frac{d s}{d \phi^{*}}=-\frac{\partial \Theta_{2}\left(s, \phi^{*}\right)}{\partial \phi^{*}} / \frac{\partial \Theta_{2}\left(s, \phi^{*}\right)}{\partial s}<0
\end{gathered}
$$

\subsubsection{The slope of the FE schedule}

Using

$$
\phi_{x}^{*}=\phi^{*} \tau\left(\frac{f_{x}}{f}\right)^{\frac{1}{\sigma-1}}=\beta \phi^{*}
$$

where $\beta=\tau\left(\frac{f_{x}}{f}\right)^{\frac{1}{\sigma-1}}>1$ and re-arranging (64) gives 


$$
\begin{gathered}
f \iint_{(\alpha, \varphi) \in D}\left[\left(\phi^{*}\right)^{1-\sigma} \phi(\alpha, \varphi)^{\sigma-1}-1\right] g(\alpha, \varphi) d \varphi d \alpha+ \\
f_{x} \iint_{(\alpha, \varphi) \in X}\left[\left(\beta \phi^{*}\right)^{1-\sigma} \phi(\alpha, \varphi)^{\sigma-1}-1\right] g(\alpha, \varphi) d \varphi d \alpha=\delta f_{e} .
\end{gathered}
$$

We differentiate the integrals $I_{D}=\iint_{(\alpha, \varphi) \in D}\left[\left(\phi^{*}\right)^{1-\sigma} \phi(\alpha, \varphi)^{\sigma-1}-1\right] g(\alpha, \varphi) d \alpha d \varphi$ and $I_{X}=\iint_{(\alpha, \varphi) \in X}\left[\left(\beta \phi^{*}\right)^{1-\sigma} \phi(\alpha, \varphi)^{\sigma-1}-1\right] g(\alpha, \varphi) d \alpha d \varphi$ with respect to $\phi^{*}$ and $s$.

Differentiating $I_{D}$. It is convenient to integrate first over $\varphi$, then over $\alpha$. Writing out the limits of integration, and substituting $\phi(\alpha, \varphi)^{\sigma-1}=\varphi^{\sigma-1} s^{\alpha(1-\sigma)}, I_{D}$ can re-written as

$$
I_{D}=\int_{0}^{1} \int_{s^{\alpha} \phi^{*}}^{\infty}\left(\phi^{*}\right)^{1-\sigma} \varphi^{\sigma-1} s^{\alpha(1-\sigma)} g(\alpha, \varphi) d \varphi d \alpha-\int_{0}^{1} \int_{s^{\alpha} \phi^{*}}^{\infty} g(\alpha, \varphi) d \varphi d \alpha,
$$

or $I_{D}=I_{D}^{1}+I_{D}^{2}$. Differentiating first with respect to $s$ gives

$$
\begin{aligned}
& \frac{\partial I_{D}^{1}}{\partial s}= \int_{0}^{1} \int_{s^{\alpha} \phi^{*}}^{\infty}\left(\phi^{*}\right)^{1-\sigma} \varphi^{\sigma-1} \alpha(1-\sigma) s^{\alpha(1-\sigma)-1} g(\alpha, \varphi) d \alpha d \varphi- \\
& \int_{0}^{1} \alpha s^{\alpha-1} \phi^{*}\left(\phi^{*}\right)^{1-\sigma}\left(s^{\alpha} \phi^{*}\right)^{\sigma-1} s^{\alpha(1-\sigma)} g\left(\alpha, s^{\alpha} \phi^{*}\right) d \alpha \\
&=(1-\sigma)\left(\phi^{*}\right)^{1-\sigma} \int_{0}^{1} \int_{s^{\alpha} \phi^{*}}^{\infty} \varphi^{\sigma-1} \alpha s^{\alpha(1-\sigma)-1} g(\alpha, \varphi) d \alpha d \varphi \\
& \frac{\partial I_{D}^{2}}{\partial s}=- {\left[\phi_{0}^{*} \alpha s^{\alpha-1} g\left(\alpha, s^{\alpha} \phi^{*}\right) d \alpha,\right.} \\
&\left.0-\int_{0}^{1} \alpha s^{\alpha-1} \phi^{*} g\left(\alpha, s^{\alpha} \phi^{*}\right) d \alpha\right]=\phi^{*} \int_{0}^{1} \alpha s^{\alpha-1} g\left(\alpha, s^{\alpha} \phi^{*}\right) d \alpha .
\end{aligned}
$$

adding the pieces together gives

$$
\frac{\partial I_{D}}{\partial s}=(1-\sigma)\left(\phi^{*}\right)^{1-\sigma} \int_{0}^{1} \int_{s^{\alpha} \phi^{*}}^{\infty} \varphi^{\sigma-1} \alpha s^{\alpha(1-\sigma)-1} g(\alpha, \varphi) d \alpha d \varphi .
$$

Differentiating next with respect to $\phi^{*}$ gives 


$$
\begin{aligned}
\frac{\partial I_{D}^{1}}{\partial \phi^{*}}= & \int_{0}^{1} \int_{s^{\alpha} \phi^{*}}^{\infty}(1-\sigma)\left(\phi^{*}\right)^{-\sigma} \varphi^{\sigma-1} s^{\alpha(1-\sigma)} g(\alpha, \varphi) d \varphi d \alpha \\
& -\int_{0}^{1} s^{\alpha}\left(\phi^{*}\right)^{1-\sigma}\left(s^{\alpha} \phi^{*}\right)^{\sigma-1} s^{\alpha(1-\sigma)} g\left(\alpha, s^{\alpha} \phi^{*}\right) d \alpha \\
= & (1-\sigma)\left(\phi^{*}\right)^{-\sigma} \int_{0}^{1} \int_{s^{\alpha} \phi^{*}}^{\infty} \varphi^{\sigma-1} s^{\alpha(1-\sigma)} g(\alpha, \varphi) d \varphi d \alpha-\int_{0}^{1} s^{\alpha} g\left(\alpha, s^{\alpha} \phi^{*}\right) d \alpha, \\
& \frac{\partial I_{D}^{2}}{\partial \phi^{*}}=-\left[0-\int_{0}^{1} s^{\alpha} g\left(\alpha, s^{\alpha} \phi^{*}\right) d \alpha\right]=\int_{0}^{1} s^{\alpha} g\left(\alpha, s^{\alpha} \phi^{*}\right) d \alpha .
\end{aligned}
$$

adding the pieces together gives

$$
\frac{\partial I_{D}}{\partial \phi^{*}}=(1-\sigma)\left(\phi^{*}\right)^{-\sigma} \int_{0}^{1} \int_{s^{\alpha} \phi^{*}}^{\infty} \varphi^{\sigma-1} s^{\alpha(1-\sigma)} g(\alpha, \varphi) d \varphi d \alpha .
$$

Differentiating $I_{X} . \quad I_{X}\left(\phi^{*}, s\right)$ differs from $I_{D}\left(\phi^{*}, s\right)$ only in the lower limit of integration over $\varphi$. We define

$$
I_{X}=\int_{0}^{1} \int_{s^{\alpha} \beta \phi^{*}}^{\infty}\left(\beta \phi^{*}\right)^{1-\sigma} \varphi^{\sigma-1} s^{\alpha(1-\sigma)} g(\alpha, \varphi) d \varphi d \alpha-\int_{0}^{1} \int_{s^{\alpha} \beta \phi^{*}}^{\infty} g(\alpha, \varphi) d \varphi d \alpha .
$$

Calculations very similar to those just above establish

$$
\begin{aligned}
\frac{\partial I_{X}}{\partial s} & =(1-\sigma)\left(\beta \phi^{*}\right)^{1-\sigma} \int_{0}^{1} \int_{s^{\alpha} \beta \phi^{*}}^{\infty} \varphi^{\sigma-1} \alpha s^{\alpha(1-\sigma)-1} g(\alpha, \varphi) d \alpha d \varphi, \\
\frac{\partial I_{X}}{\partial \phi^{*}} & =(1-\sigma)\left(\phi^{*}\right)^{-\sigma} \beta^{1-\sigma} \int_{0}^{1} \int_{s^{\alpha} \beta \phi^{*}}^{\infty} \varphi^{\sigma-1} s^{\alpha(1-\sigma)} g(\alpha, \varphi) d \varphi d \alpha .
\end{aligned}
$$

Summarizing the derivatives of the FE schedule. Putting the pieces of the total derivative together,

$$
\begin{aligned}
\frac{\partial \Theta_{2}}{\partial \phi^{*}} & =f \frac{\partial I_{D}}{\partial \phi^{*}}+f_{x} \frac{\partial I_{X}}{\partial \phi^{*}} \\
& =(1-\sigma)\left(\phi^{*}\right)^{-\sigma}\left[\begin{array}{c}
f \int_{0}^{1} \int_{s^{\alpha} \phi^{*}}^{\infty} \varphi^{\sigma-1} s^{\alpha(1-\sigma)} g(\alpha, \varphi) d \varphi d \alpha \\
+f_{x} \beta^{1-\sigma} \int_{0}^{1} \int_{s^{\alpha} \beta \phi^{*}}^{\infty} \varphi^{\sigma-1} s^{\alpha(1-\sigma)} g(\alpha, \varphi) d \varphi d \alpha
\end{array}\right]<0,
\end{aligned}
$$




$$
\begin{aligned}
\frac{\partial \Theta_{2}}{\partial s} & =\frac{f \partial I_{D}}{\partial s}+f_{x} \frac{\partial I_{X}}{\partial s} \\
& =(1-\sigma)\left(\phi^{*}\right)^{1-\sigma}\left[\begin{array}{c}
f \int_{0}^{1} \int_{\alpha^{\alpha} \phi^{*}}^{\infty} \varphi^{\sigma-1} \alpha s^{\alpha(1-\sigma)-1} g(\alpha, \varphi) d \alpha d \varphi \\
+f_{x} \beta^{1-\sigma} \int_{0}^{1} \int_{s^{\alpha} \beta \phi^{*}}^{\infty} \varphi^{\sigma-1} \alpha s^{\alpha(1-\sigma)-1} g(\alpha, \varphi) d \alpha d \varphi
\end{array}\right]<0 .
\end{aligned}
$$

The terms in brackets are strictly positive, while $(1-\sigma)<0$, so both derivatives are strictly negative. We have thus confirmed the slope of the FE schedule given by (68).

\subsubsection{The slope of the LME schedule}

A direct calculus approach to establishing the slope of the LME schedule (63) is infeasible, so we proceed heuristically. We begin by re-writing the left hand side of (63) as an unskilled labor weighted average of each active firms skill intensity. The definitions of $\tilde{H}_{d v}$ and $\tilde{L}_{d v}$ that appear in (63) are

$$
\begin{gathered}
\tilde{H}_{d v}(\alpha, \varphi, s)=\alpha s^{(1-\sigma) \alpha-1} \varphi^{\sigma-1}, \\
\tilde{L}_{d v}(\alpha, \varphi, s)=(1-\alpha) s^{(1-\sigma) \alpha} \varphi^{\sigma-1} .
\end{gathered}
$$

Dividing (71) by (72) gives

$$
\widetilde{h l}(\alpha, s)=\frac{\alpha}{1-\alpha} s^{-1} .
$$

Define the numerator and denominator on the left hand side of $(63)$ as $\widetilde{H}_{v}\left(s, \phi^{*}\right)$ and $\widetilde{L}_{v}\left(s, \phi^{*}\right)$ respectively, so that we have

$$
\begin{aligned}
H_{v} & =M \rho^{\sigma} R P^{\sigma-1} \times \widetilde{H}_{v}\left(s, \phi^{*}\right), \\
L_{v} & =M \rho^{\sigma} R P^{\sigma-1} \times \widetilde{L}_{v}\left(s, \phi^{*}\right) .
\end{aligned}
$$

and the following holds in equilibrium,

$$
\frac{H_{v}\left(s, \phi^{*}\right)}{L_{v}\left(s, \phi^{*}\right)}=\frac{\widetilde{H}_{v}\left(s, \phi^{*}\right)}{\widetilde{L}_{v}\left(s, \phi^{*}\right)}=\frac{H}{L} .
$$

Using the tautology $\widetilde{h l} \times \tilde{L}_{d v}=\tilde{H}_{d v}$, the definition of $\widetilde{L}_{v}\left(s, \phi^{*}\right)$, defining $\theta\left(\alpha, \varphi, s, \phi^{*}\right)=\tilde{L}_{d v}(\alpha, \varphi, s) / \widetilde{L}_{v}\left(s, \phi^{*}\right)$ and substituting, we re-write (63) as

$$
\begin{aligned}
\frac{H}{L}= & \iint_{(\alpha, \varphi) \in D} \widetilde{h l}(\alpha, s) \theta\left(\alpha, \varphi, s, \phi^{*}\right) g(\alpha, \varphi) d \alpha d \varphi+ \\
& \tau^{1-\sigma} \iint_{(\alpha, \varphi) \in X} \widetilde{h l}(\alpha, s) \theta\left(\alpha, \varphi, s, \phi^{*}\right) g(\alpha, \varphi) d \alpha d \varphi .
\end{aligned}
$$

The interpretation of $\theta\left(\alpha, \varphi, s, \phi^{*}\right)$ is the share of unskilled labor employed by firms characterized by $(\alpha, \varphi)$ at the aggregate values $\left(s, \phi^{*}\right)$. By the definition of $\widetilde{L}_{v}\left(s, \phi^{*}\right)$,

$$
\iint_{(\alpha, \varphi) \in D} \theta\left(\alpha, \varphi, s, \phi^{*}\right) g(\alpha, \varphi) d \varphi d \alpha+\tau^{1-\sigma} \iint_{(\alpha, \varphi) \in X} \theta\left(\alpha, \varphi, s, \phi^{*}\right) g(\alpha, \varphi) d \varphi d \alpha=1
$$


For firms that export, their total unskilled labor share is $\theta\left(\alpha, \varphi, s, \phi^{*}\right) \times\left(1+\tau^{1-\sigma}\right)$. Equation (74) is useful because it shows that the aggregate skill ratio is a weighted average of the firm-level skill ratios.

Now consider an incremental increase in the cutoff $\phi^{*}$. By definition, this will lead to exit of the highest cost firms, with their weight in relative skill demand going to zero. By the assumption that technology is skill-biased, these firms are less skill-intensive than the firms that do not exit, causing an incipient relative excess demand for skilled labor. Thus to maintain relative labor market equilibrium, the skill premium $s$ must rise when $\phi^{*}$ rises. Thus we conclude that the LME schedule is upward sloping in $\left(s, \phi^{*}\right)$ space. This concludes the demonstration that equilibrium is unique.

\subsection{Proof of Proposition 1}

Our proof of Proposition 1 proceeds by analyzing shifts in the LME and FE curves in the movement from autarky to costly trade. Since both curves shift up, the equilibrium skill premium must rise (see Figure A1).

\subsubsection{Opening to trade causes shift up in FE curve}

Consider the free entry condition (64). Under autarky, $X=\varnothing$ so (64) reduces to

$$
\Theta_{2}\left(s, \phi^{*}\right)=f \int_{0}^{1} \int_{s^{\alpha} \phi^{*}}^{\infty}\left[\left(\frac{\phi(\alpha, \varphi)}{\phi^{*}}\right)^{\sigma-1}-1\right] g(\alpha, \varphi) d \alpha d \varphi=\delta f_{e},
$$

where we have written out the limits of integration corresponding to the set of active firms $D$. Since the right hand side of (64) does not change in the move from autarky to costly trade, while we add a strictly positive integral $f_{x} \iint_{(\alpha, \varphi) \in X}\left[\left(\frac{\phi(\alpha, \varphi)}{\phi_{x}^{*}}\right)^{\sigma-1}-1\right] g(\alpha, \varphi) d \alpha d \varphi$, the first integral in (64) must get smaller. Holding $\phi^{*}$ fixed, inspection of the limits of integration confirms that this requires an increase in $s$, which corresponds to shift up of the FE curve (see Figure A1).

\subsubsection{Opening to trade causes shift up in LME curve}

In autarky, (74) reduces to

$$
\int_{0}^{1} \int_{s^{\alpha} \phi^{*}}^{\infty} \widetilde{h l}(\alpha, s) \theta\left(\alpha, \varphi, s, \phi^{*}\right) g(\alpha, \varphi) d \varphi d \alpha=\frac{H}{L} .
$$

At the autarky equilibrium values of $s$ and $\phi^{*}$, consider an opening to costly trade. Two effects are immediate. First, because of fixed and variable export costs, only the most competitive firms will export, increasing their labor demand weights by the factor $\left(1+\tau^{1-\sigma}\right)$ relative to the weights of non-exporters. Second, because of skill bias, newly exporting firms are more skill intensive on average than non-exporters. As a consequence of these two effects, relative skill demand increases when costly trade opens up. At the autarky equilibrium cutoff $\phi^{*}, s$ must increase to satisfy (74), which corresponds to an upward shift in the LME curve. 


\subsection{Proof of Proposition 2}

When there is no skill bias, we can write the joint density as $g(\alpha, \varphi)=g_{\alpha}(\alpha) g_{\varphi}(\varphi)$. The marginal distributions are assumed to be uniform on $[0,1]$ and Pareto on $[1, \infty)$ respectively

$$
g_{\alpha}(\alpha)=1, \quad g_{\varphi}(\varphi)=k \varphi^{-(k+1)} .
$$

Using these functional forms, the integrals in the numerator and denominator of (63) can be computed. Assuming $k>\sigma-1$, and defining the parameter collection

$$
\Delta=\frac{\left(\phi^{*}\right)^{\sigma-1-k}\left(s^{k}-1-k \log s\right)}{k(k-\sigma+1)[\log s]^{2}},
$$

the integrals are

$$
\begin{gathered}
\iint_{(\alpha, \varphi) \in D} \tilde{H}_{d v} g(\alpha, \varphi) d \varphi d \alpha=\int_{0}^{1} \int_{s^{\alpha} \phi^{*}}^{\infty} \alpha s^{\alpha(1-\sigma)-1} \varphi^{\sigma-1} k \varphi^{-(k+1)} d \varphi d \alpha=s^{-1-k} \Delta, \\
\tau^{1-\sigma} \iint_{(\alpha, \varphi) \in X} \tilde{H}_{d v} g(\alpha, \varphi) d \varphi d \alpha=\tau^{1-\sigma} \beta^{\sigma-1-k} s^{-1-k} \Delta \\
\iint_{(\alpha, \varphi) \in D} \tilde{L}_{d v} g(\alpha, \varphi) d \varphi d \alpha=\int_{0}^{1} \int_{s^{\alpha} \phi^{*}}^{\infty}(1-\alpha) s^{\alpha(1-\sigma)} \varphi^{\sigma-1} k \varphi^{-(k+1)} d \varphi d \alpha=\Delta, \\
\tau^{1-\sigma} \iint_{(\alpha, \varphi) \in X} \tilde{L}_{d v} g(\alpha, \varphi) d \varphi d \alpha=\tau^{1-\sigma} \beta^{\sigma-1-k} \Delta .
\end{gathered}
$$

Substituting and simplifying, (63) evaluates to

$$
\Theta_{1}(s)=\frac{s^{k}-1-k \log s}{s+s^{k+1}(k \log s-1)}=\frac{H}{L} .
$$

Equation (76) is a single equation in the single unknown $s$. Differentiation establishes

$$
\frac{d \Theta_{1}}{d s}=\frac{(1-k)\left(1-s^{k}\right)^{2}+k \log s\left(1-s^{2 k}+k(k+1) s^{k} \log s\right)}{\left[s+s^{k+1}(k \log s-1)\right]^{2}}<0,
$$

where the inequality holds for any $s>1$. Thus, the solution $s$ of (76) is unique, and monotonically decreasing in $H / L$. By inspection, the solution does not depend on any trade cost parameters, which proves that the skill premium is unaffected by opening to trade or trade liberalization in this case. This completes the proof of Proposition 2. A final note is that since $\lim _{s \rightarrow 1} \Theta_{1}(s)=1,(76)$ implies $s>1$ if and only if $H / L<1$. If $H / L \geq 1, s=1$ by our assumption that skilled workers can perform unskilled jobs but not vice versa. 


\section{APPENDIX 2}

\subsection{Applying the Plackett copula}

We explain here how we simulate the primitive joint distribution $G(\alpha, \varphi)$. We take as given the parameters of the marginal distributions $\alpha \sim \operatorname{Beta}(a, b)$ and $\varphi \sim \operatorname{Pareto}(m, k)$ ( $m$ is the cutoff and $k$ is the shape parameter) and the Plackett association parameter $\theta$. First we generate draws from a joint uniform $[0,1]$ distribution following Nelsen (2006) (exercise 3.38 on page 99):

1. Draw two independent vectors of length $I$ from a uniform $[0,1]$ distribution, $U$ and $X$.

2. Set

$$
\begin{aligned}
a_{i} & =X_{i}\left(1-X_{i}\right) \\
b_{i} & =\theta+a_{i}(\theta-1)^{2} \\
c_{i} & =2 a_{i}\left(U_{i} \theta^{2}+1-U_{i}\right)+\theta\left(1-2 a_{i}\right) \\
d_{i} & =\sqrt{\theta} \cdot \sqrt{\theta+4 a_{i} U_{i}\left(1-U_{i}\right)(1-\theta)^{2}} .
\end{aligned}
$$

3. Set $V_{i}=\left[c_{i}-\left(1-2 X_{i}\right) d_{i}\right] / 2 b_{i}$ for $i=1,2, \ldots I$.

The vector $V$ is distributed uniform $[0,1]$. The pair $(U, V)$ has the joint distribution function $C_{\theta}(u, v)$, where $C_{\theta}(u, v)$ is the Plackett copula. The correlation between $U$ and $V$ is governed by $\theta$; it is positive for $\theta>1$. One can think of $U$ and $V$ as marginal distribution functions. Using $(U, V)$ we obtain $\alpha$ and $\varphi$ by the inverses of the marginal distribution functions: $\alpha=G_{\alpha}^{-1}(U)$ and $\varphi=G_{\varphi}^{-1}(V)$. The pair $(\alpha, \varphi)$ follows the primitive joint distribution $G(\alpha, \varphi)=C_{\theta}\left(G_{\alpha}(\alpha), G_{\varphi}(\varphi)\right)$.

\subsection{Solution for the symmetric open economy equilibrium}

We take all the parameters, as well as the primitive distribution $G(\alpha, \varphi)$, as given. We solve for three endogenous variables: $\phi^{*}, w$ and $s$. All other endogenous variables and aggregates are functions of those variables. We solve for both nominal wages using gold as the numeraire. This makes the search for the equilibrium more efficient and robust. In addition, using gold as numeraire makes interpretation of changes of nominal values straightforward.

Draw $I$ firms (technologies) from $G(\alpha, \varphi)$, denoted $\left\{(\alpha, \varphi)_{i}\right\}_{i=1}^{I}$. This set is fixed throughout the search for the equilibrium.

1. Guess initial values $\left(\phi_{0}^{*}, w_{0}, s_{0}\right)$ and set $\phi_{x}^{*}=\phi_{0}^{*} \tau\left(f_{x} / f\right)^{\frac{1}{\sigma-1}}$.

2. Set $\phi_{i}=\varphi_{i} /\left(s_{0}^{\alpha_{i}} w_{0}^{1-\alpha_{i}}\right)$ for all $i$. Collect surviving firms such that $\phi_{i}>\phi_{0}^{*}$; this leaves us with $J$ active firms: $\left\{\phi_{j}\right\}_{j=1}^{J}$ and the commensurate $\left\{(\alpha, \varphi)_{j}\right\}_{j=1}^{J}$. Collect exporters such that $\phi_{i}>\phi_{x}^{*}$; this leaves us with $T$ exporters: $\left\{\phi_{t}\right\}_{t=1}^{T}$ and the commensurate $\left\{(\alpha, \varphi)_{t}\right\}_{t=1}^{T}$. Finally, set $\chi_{d}=J / I$ (probability of entry) and $\chi=T / J$ (export probability conditional on entry).

3. Compute three deviations from equilibrium relationships

$$
\begin{aligned}
\Delta_{f e} & =f \frac{1}{J} \sum_{j=1}^{J}\left[\left(\phi_{j} / \phi_{0}^{*}\right)^{\sigma-1}-1\right]+f_{x} \chi \frac{1}{T} \sum_{t=1}^{T}\left[\left(\phi_{t} / \phi_{x}^{*}\right)^{\sigma-1}-1\right]-\delta f_{e} / \chi_{d} \\
\Delta_{\text {rle }} & =\frac{\frac{1}{J} \sum_{j=1}^{J} \alpha_{j} \phi_{j}^{\sigma-1}+\chi \tau^{1-\sigma} \frac{1}{T} \sum_{t=1}^{T} \alpha_{t} \phi_{t}^{\sigma-1}}{\frac{1}{J} \sum_{j=1}^{J}\left(1-\alpha_{j}\right) \phi_{j}^{\sigma-1}+\chi \tau^{1-\sigma} \frac{1}{T} \sum_{t=1}^{T}\left(1-\alpha_{t}\right) \phi_{t}^{\sigma-1}} \cdot \frac{w_{0}}{s_{0}}-\frac{H}{L} \\
\Delta_{\text {gold }} & =H s+L w-G / 2,
\end{aligned}
$$

where $G$ is the amount of gold in the world. 
Equilibrium is found when all $\Delta$ are all equal to zero. We search for $\left(\phi_{0}^{*}, w_{0}, s_{0}\right)$ such that these conditions are met. We use the numerical solver fsolve in Matlab to do this.

The numerical equilibrium relationships are written differently from those in the main text to reflect the computation methodology; however, they are the same as in the main text. All averages are approximations of means, and take into account the truncations and correct distribution functions. For example,

$$
\frac{1}{J} \sum_{j=1}^{J}\left[\left(\phi_{j} / \phi_{0}^{*}\right)^{\sigma-1}-1\right]
$$

approximates

$$
\iint_{(\alpha, \varphi) \in D}\left[\left(\frac{\phi(\alpha, \varphi)}{\phi^{*}}\right)^{\sigma-1}-1\right] \frac{g(\alpha, \varphi)}{\chi_{d}} d \alpha d \varphi
$$

not

$$
\iint_{(\alpha, \varphi) \in D}\left[\left(\frac{\phi(\alpha, \varphi)}{\phi^{*}}\right)^{\sigma-1}-1\right] g(\alpha, \varphi) d \alpha d \varphi,
$$

because $\left\{\phi_{j}\right\}_{j=1}^{J}$ and the commensurate $\left\{(\alpha, \varphi)_{j}\right\}_{j=1}^{J}$ are both in $D$ by construction and are both distributed according to $g(\alpha, \varphi) / \chi_{d}$. So while the free entry condition and relative labor equilibrium equation in the main text do not involve $\chi_{d}$ or $\chi$, here we must correct the means by the relevant probabilities to match these relationships in the text.

\subsection{Solution for the autarky equilibrium}

The solution of the model for an economy in autarky is very similar to the solution for the symmetric open economy case with one difference: we do not have a set of exporters. We solve for three endogenous variables: $\phi^{*}, w$ and $s$. All other endogenous variables and aggregates are functions of those variables. The three deviations from autarky equilibrium relationships are

$$
\begin{aligned}
\Delta_{f e} & =f \frac{1}{J} \sum_{j=1}^{J}\left[\left(\phi_{j} / \phi_{0}^{*}\right)^{\sigma-1}-1\right]-\delta f_{e} / \chi_{d} \\
\Delta_{\text {rle }} & =\frac{\frac{1}{J} \sum_{j=1}^{J} \alpha_{j} \phi_{j}^{\sigma-1}}{\frac{1}{J} \sum_{j=1}^{J}\left(1-\alpha_{j}\right) \phi_{j}^{\sigma-1}} \cdot \frac{w_{0}}{s_{0}}-\frac{H}{L} \\
\Delta_{\text {gold }} & =H s+L w-G .
\end{aligned}
$$

Equilibrium is found when all $\Delta$ are all equal to zero. We search for $\left(\phi_{0}^{*}, w_{0}, s_{0}\right)$ such that these conditions are met. We use the numerical solver $f$ solve in Matlab to do this.

\subsection{Solution for the equilibrium with differences in factor endowments}

\subsubsection{Mathematical details}

Solving for the equilibrium with differences in factor endowments involves all endogenous variables, including aggregates, simultaneously. However, it is possible to compartmentalize the equilibrium as follows. Define the following vector of seven equilibrium variables

$$
\mu^{\prime}=\left(s^{A}, w^{B}, s^{B}, \phi^{* B}, \phi^{* B}, P^{A}, P^{B}\right)
$$

where we set $w^{A}$ as numeraire. The remainder of the equilibrium values are given by

$$
\eta^{\prime}=\left(R^{A}, R^{B}, \phi_{x}^{* A}, \phi_{x}^{* B}, \chi_{d}^{A}, \chi_{d}^{B}, \chi^{A}, \chi^{B}, \tilde{\phi}^{A}, \tilde{\phi}^{B}, \tilde{\phi}_{x}^{A}, \tilde{\phi}_{x}^{B}, M^{A}, M^{B}\right)
$$


The entire equilibrium is determined by a system of 21 equations, partitioned as follows

$$
F(\mu, \eta)=\left[\begin{array}{l}
f(\mu, \eta) \\
g(\mu, \eta)
\end{array}\right]=0
$$

$f$ involves three factor market clearing conditions (equations (55) and (56) for each country, with one equation discarded as redundant), two free entry conditions (equation (27) for each country), and price indices (57) and (58). $g$ involves aggregate revenue equations (42), the relationships between entry and exporting cutoffs (53) and (54), probability equations (21) and (22), average competitiveness (23) and (24), and firm mass equations (44).

Consider $g(\mu, \eta)=0$. By the implicit function theorem, there exists a function $\eta=\eta(\mu)$ such that $g[\mu, \eta(\mu)]=0$. The function $\eta(\mu)$ exists because (a) $g$ is continuously differentiable; and (b) given the particular partition we chose, the Jacobian matrix $\left[\partial g / \partial \eta^{\prime}\right]$ is nonsingular for all admissible values of $\eta$. We use $\eta(\mu)$ in

$$
F[\mu, \eta(\mu)]=0
$$

to find values of $\mu$ that satisfy all equilibrium conditions.

\subsubsection{Numerical solution}

We take all the parameters, as well as the primitive distribution $G(\alpha, \varphi)$, as given. We solve for 8 endogenous variables: $s_{0}^{A}, w_{0}^{A}, s_{0}^{B}, w_{0}^{B}, \phi_{0}^{* A}, \phi_{0}^{* B}, P_{0}^{A}$ and $P_{0}^{B}$. All other endogenous variables and aggregates are functions of those variables. We solve for all nominal variables using gold as the numeraire. This makes the search for the equilibrium more efficient and robust. In addition, using gold as numeraire makes interpretation of changes of nominal values straightforward.

Draw $I$ firms (technologies) from $G(\alpha, \varphi)$, denoted $\left\{(\alpha, \varphi)_{i}\right\}_{i=1}^{I}$. This set will not change throughout the search for the equilibrium.

1. Guess initial values

$$
\mu_{0}^{\prime}=\left(s_{0}^{A}, w_{0}^{A}, s_{0}^{B}, w_{0}^{B}, \phi_{0}^{* A}, \phi_{0}^{* B}, P_{0}^{A}, P_{0}^{B}\right)
$$

and set

$$
\begin{aligned}
R^{c} & =H^{c} s_{0}^{c}+L^{c} w_{0}^{c} \\
\phi_{x}^{* c} & =\phi_{0}^{* c} \tau\left(\frac{P_{0}^{c}}{P_{0}^{c^{\prime}}}\right)\left(\frac{R^{c}}{R^{c^{\prime}}} \frac{f_{x}}{f}\right)^{\frac{1}{\sigma-1}} .
\end{aligned}
$$

for each country $c \in\{A, B\}$ and $c^{\prime}=\{A, B\} \backslash c$.

2. Set $\phi_{i}^{c}=\varphi_{i} /\left(\left(s_{0}^{c}\right)^{\alpha_{i}}\left(w_{0}^{c}\right)^{1-\alpha_{i}}\right)$ for all $i$. Collect surviving firms such that $\phi_{i}^{c}>\phi_{0}^{* c}$; this leaves us with $J^{c}$ active firms: $\left\{\phi_{j}^{c}\right\}_{j=1}^{J^{c}}$ and the commensurate $\left\{(\alpha, \varphi)_{j}\right\}_{j=1}^{J^{c}}$. Collect exporters such that $\phi_{i}^{c}>\phi_{x}^{* c}$; this leaves us with $T^{c}$ exporters: $\left\{\phi_{t}^{c}\right\}_{t=1}^{T^{c}}$ and the commensurate $\left\{(\alpha, \varphi)_{t}\right\}_{t=1}^{T^{c}}$. Note that $\phi_{i}^{c}$ are indexed by country because the wages are different. 
3. Compute the following auxiliary objects:

$$
\begin{aligned}
\chi^{c} & =T^{c} / J^{c} \\
\chi_{d}^{c} & =J^{c} / I \\
M^{c} & =\frac{N}{\sigma\left(\frac{\delta}{\chi_{d}^{c}} f_{e}+f+\chi^{c} f_{x}\right)} \\
\widetilde{\phi}^{c} & =\left[\frac{1}{J^{c}} \sum_{j=1}^{J^{c}}\left(\phi_{j}^{c}\right)^{\sigma-1}\right]^{\frac{1}{\sigma-1}} \\
\widetilde{\phi}_{x}^{c} & =\left[\frac{1}{T^{c}} \sum_{t=1}^{T^{c}}\left(\phi_{t}^{c}\right)^{\sigma-1}\right]^{\frac{1}{\sigma-1}} \\
\Upsilon^{c} & =\tau^{1-\sigma}\left(\frac{P^{c^{\prime}}}{P^{c}}\right)^{\sigma-1}\left(\frac{R^{c^{\prime}}}{R^{c}}\right) .
\end{aligned}
$$

4. For each country $c$ compute four deviations from equilibrium relationships

$$
\begin{aligned}
\Delta_{f e}^{c} & =f \frac{1}{J^{c}} \sum_{j=1}^{J^{c}}\left[\left(\phi_{j} / \phi_{0}^{* c}\right)^{\sigma-1}-1\right]+f_{x} \chi^{c} \frac{1}{T^{c}} \sum_{t=1}^{T^{c}}\left[\left(\phi_{t}^{c} / \phi_{x}^{*}\right)^{\sigma-1}-1\right]-\delta f_{e} / \chi_{d}^{c} \\
\Delta_{p}^{c} & =\left[M^{c}\left(\rho \widetilde{\phi}^{c}\right)^{\sigma-1}+\chi^{c^{\prime}} M^{c^{\prime}} \tau^{1-\sigma}\left(\rho \widetilde{\phi}_{x}^{B}\right)^{\sigma-1}\right]^{\frac{1}{1-\sigma}}-P_{0}^{A} \\
\Delta_{h}^{c} & =M^{c} \rho^{\sigma}\left(P_{0}^{c}\right)^{\sigma-1} R^{c}\left[\frac{1}{J^{c}} \sum_{j=1}^{J^{c}} \alpha_{j}\left(\phi_{j}^{c}\right)^{\sigma-1}+\chi^{c} \Upsilon^{c} \frac{1}{T^{c}} \sum_{t=1}^{T^{c}} \alpha_{t}\left(\phi_{t}^{c}\right)^{\sigma-1}\right] / s_{0}^{c}-H^{c} \\
\Delta_{l}^{c} & =M^{c} \rho^{\sigma}\left(P_{0}^{c}\right)^{\sigma-1} R^{c}\left[\frac{1}{J^{c}} \sum_{j=1}^{J^{c}}\left(1-\alpha_{j}\right)\left(\phi_{j}^{c}\right)^{\sigma-1}+\chi^{c} \Upsilon^{c} \frac{1}{T^{c}} \sum_{t=1}^{T^{c}}\left(1-\alpha_{t}\right)\left(\phi_{t}^{c}\right)^{\sigma-1}\right] / w_{0}^{c}-L^{c} .
\end{aligned}
$$

In addition, compute the deviation from global nominal output,

$$
\Delta_{\text {gold }}=R^{A}+R^{B}-G,
$$

where $G$ is the amount of gold in the world. We do not use $\Delta_{l}^{B}$, so that the system is identified exactly.

Equilibrium is found when all $\Delta$ are all equal to zero. We search for $\mu_{0}$ such that these conditions are met. We use the numerical solver fsolve in Matlab to do this.

Some of the numerical equilibrium relationships are written differently from those in the main text to reflect the computation methodology; however, they are the same as in the main text. All averages are approximations of means, and take into account the truncations and correct distribution functions; see Section 6.2. 